\title{
Assessment of Organ and Effective Doses Received by Paediatric Patients Undergoing Computed Tomography Examinations in Three Hospitals in Brazzaville, Congo Republic: An Urgent Necessity for Regulatory Control
}

\section{J. Bazoma ${ }^{\text {b, }}$, G. B. Dallou a, b *, P. Ondo Meye ${ }^{\text {d, e }}$, C. Bouka Biona ${ }^{\text {a, b}}$, Saïdou ${ }^{\text {f, g, G. H. Ben-Bolie }}{ }^{\mathrm{e}}$}

${ }^{a}$ Université Marien Ngouabi, Faculté des Sciences et Techniques, BP 69 Brazzaville, Congo

${ }^{b}$ Institut National de Recherche en Sciences Exactes et Naturelles, PB 2400 Brazzaville, Congo.

' Centre Hospitalier Universitaire de Brazzaville, BP 32 Brazzaville, Congo

d Direction Générale de la Radioprotection et de la Sûreté Nucléaire, Ministère de l'Energie et des Ressources Hydrauliques, BP 1172 Libreville, Gabon

e Laboratory of Atomic, Moleculary and Nulear Physics, Department of Physics, Faculty of Science, University of Yaounde I, P.O. Box 812 Yaounde, Cameroon

${ }_{\mathrm{f}}$ Nuclear Physics Laboratory, Faculty of Science, University of Yaounde I, P.O. Box 812 Yaounde, Cameroon g Nuclear Technology Section, Institute of Geological and Mining Research, P.O. Box 4110 Yaounde, Cameroon ·Corresponding author: dg_blanc@yahoo.fr, +242064486554

\section{Article Info}

Volume 8, Issue 5

Page Number : $527-550$

\section{Publication Issue}

September-October-2021

\section{Article History}

Accepted : 16 Oct 2021

Published : 30 Oct 2021

\section{ABSTRACT}

The present study aimed at estimating organ and effective doses from computed tomography (CT) scans of paediatric patients in three hospitals in Brazzaville, Congo Republic. A total of 136 data on paediatric patients, from 0.25 (3 months) to 15 years old, who underwent head, chest, abdomen - pelvis (AP) and chest - abdomen - pelvis (CAP) CT scans was considered.

The approach followed in the present study to compute organ doses was to use pre-calculated volume CT dose index (CTDIvol) - and 100 milliampere-second (mAs) - normalized organ doses determined by Monte Carlo (MC) simulation. Effective dose were then derived using the international commission on radiological protection (ICRP) publications 60 and 103 formalism. For comparison purposes, effective dose were also computed using dose-length product (DLP) - to - effective dose conversion factors. A relatively high variation in organ and effective doses was observed in each age group due to the dependence of patient dose on the practice of technicians who perform the CT scan within the same facility or from one facility to another, patient size and lack of adequate training of technicians. In the particular case of head scan, the brain and the eye lens were delivered maximum absorbed doses of 991.81 mGy and $1176.51 \mathrm{mGy}$, respectively (age group 10-15 y). The maximum absorbed dose determined for the red bone marrow was $246.08 \mathrm{mGy}$ (age group 1-5 y). This is of concern as leukaemia and brain tumours are the most common childhood cancers and as the ICRP recommended absorbed dose 
threshold for induction of cataract is largely exceeded. Effective doses derived from MC calculations and ICRP publications 60 and 103 tissues weighting factors showed a 0.40-17.61 \% difference while the difference between effective doses derived by the use of $\mathrm{k}$ - factors and those obtained by MC calculations ranges from 0.06 to $224.87 \%$. The study has shown that urgent steps should be taken in order to significantly reduce doses to paediatric patients to levels observed in countries where dose reduction techniques are successfully applied.

Keywords : Computed tomography, paediatric patients, organ dose, effective dose

\section{INTRODUCTION}

Medical uses of ionizing radiation are among the longest established applications of ionizing radiation. These medical uses bring considerable public health benefits. However, ionizing radiation can cause harm. A systematic approach should be put in place and followed to ensure that there is a balance between utilizing the benefits from medical uses of ionizing radiation and minimizing the risk of radiation effects to patients, workers and members of the public [1].

Medical exposures accounts for $98 \%$ of the contribution from all the artificial sources and $43 \%$ of the total radiation dose to the world population due to medical exposure arises from CT scanning [2]. At radiation dose levels encountered in diagnostic radiology, the health effects that both adult and paediatric patients are most likely exposed to are cancers [3]. Risk projection models show that, in a few decades, $1.5-2 \%$ of all cancers in the United States may be attributable to the use of CT [4]. Children are considered at greater risk of radiationinduced cancer than adults are owing to their higher biological sensitivity to ionizing radiation and to their longer life expectancy, resulting in more time for potential radiation-induced cancer to develop. Therefore, medical uses of ionizing radiation, particularly CT, should be subject to the principles of justification and optimization. That is, the diagnostic benefits of exposure should be weighted against the detriment they might cause, with account taken of the benefits and risks of available alternative techniques that do not involve ionizing radiation for the former and, keeping the exposure of patients to the minimum necessary to achieve the required diagnostic objective for the latter.

The dose metrics commonly used in CT are the

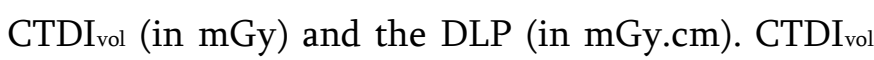
quantifies the relative intensity of the radiation that is incident on the patient. DLP, which is the product of CTDI $_{\text {vol }}$ and scan length, quantifies the total amount of radiation patients receive during a given scan [5]. Current CT scanners generate patient CTDI $_{\text {vol }}$ and DLP that are measured in 16 - and $32-\mathrm{cm}$ diameter polymethyl methacrylate (PMMA) phantoms. The preferred radiation dose quantity in medical imaging is the effective dose $(E$, in $\mathrm{mSv})$ as it can be of value for the purposes of comparing radiation doses from different diagnostic procedures and for comparing the use of similar technologies and procedures in different hospitals and countries as well as the use of different technologies for the same medical examination $[6,7]$. $E$ provides a conceptual whole-body dose that has the same risk as a dose delivered to just part of the body. Although effective dose is a suitable quantity for the reasons mentioned above, the equivalent dose $\left(H_{T}\right.$, in 
$\mathrm{mSv})$ or the absorbed dose ( $D_{T}$, in $\left.\mathrm{mGy}\right)$ to irradiated tissues $T$ is the relevant quantity for risk - benefit assessments [7]. There are two approaches for estimating patient organ dose in CT $[8,9]$ : (1) an empirical dose measurement using physical anthropomorphic phantom in conjunction with various type of dosimeters and (2) software dose calculations using computational MC phantoms. The use of the latter approach may provide the closest estimate for individualized patient dosimetry and is generally considered the gold standard among the different dosimetry techniques. Effective dose (and equivalent dose) are then derived using ICRP radiation $\left(W_{R}\right)$ and organ or tissue $\left(W_{T}\right)$ weighting factors.

The present study aimed at estimating organ and effective doses from CT scans of paediatric patients in three hospitals in Brazzaville, Congo Republic. The results obtained were compared to those found in the literature and strategies for dose reduction in CT were discussed.

\section{METHODS AND MATERIAL}

\section{II.1-Materials}

The features of the three CT machines involved in the study such as the brand, the model, the serial number, the year of manufacture, the year of installation and other pertinent information are given in Table 1.

\section{II.2-Methods}

\section{II.2.1-Collection of data}

A total of 136 data from paediatric patients were manually collected in three computed tomography facilities of three hospitals in Brazzaville, Republic of Congo. These facilities were selected on the basis of the frequency of examinations performed and the possibility of directly collecting the relevant radiation dose and technical parameters displayed on the console of the CT machines. Data were collected on the period from 2 June 2018 to 24 July 2019.
A permission to undertake the study, which mentioned that the identity of patients will be kept confidential and will not be collected, was granted by the management of the hospitals involved. The data collected were handled as confidential data and the identity of the participating hospitals was not disclosed. However, if needed, any participating hospital can have access to its own data.

The 136 data collected are relative to 4 examination types. These correspond to the anatomical regions explored or to organs, depending on the precision of the information available. These are head, chest, AP and CAP. It is also worth mentioning that, in this study, examinations with contrast are in fact doublephase examinations, the first phase being performed without contrast and the second with contrast.

The examination type, the number of acquisitions, the age and sex of the patient along with the CTDI ${ }_{\text {vol }}$ and DLP associated with the examination were collected.

\section{II.2.2-Calculation of organ and effective doses}

The approach followed in the present study to compute organ doses was to use pre - calculated organ dose matrix developed by Lee et al [9] by MC simulation. These dose matrix, defined as organ doses normalized by CTDI $\mathrm{vol}_{\mathrm{v}}$ and $100 \mathrm{mAs}$ (units of $\mathrm{mGy} / 100 \mathrm{mAs} \mathrm{mGy}$ ), were developed for 5 ages (newborn, 1-year, 5-year, 10-year and 15-year), two gender (male and female), 33 organs and 3 tube potentials $\left(80,100\right.$ and $120 \mathrm{kV}_{\mathrm{p}}$ ). The normalization

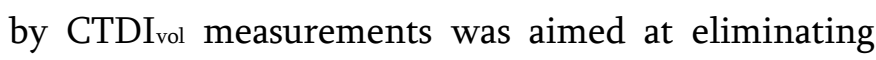
scanner - specific characteristics. The formula used to compute organ doses was

$$
D_{T}=C T D I_{v o l} \times \frac{m A s}{100} \times D_{N}
$$

where $D_{T}$ is the dose to organ or tissue $T, \mathrm{CTDI}_{\mathrm{vol}}$ is the volume CT dose index at a given $\mathrm{mAs}$ and $120 \mathrm{kV}_{\mathrm{p}}$, $D_{N}$ is the CTDI $I_{\text {vol }}$ - and $100 \mathrm{mAs}$ - normalized organ absorbed dose for $120 \mathrm{kV}_{\mathrm{p}}$, as all the examinations were performed at this tube voltage value (Table 3 ). 
Linear interpolation was carried out to compute $D_{N}$ values for age values between the 5 ages mentioned above and a mean value was calculated for each age group considered in the study $(<1 \mathrm{y}, 1-4 \mathrm{y}, 5-9 \mathrm{y}$, and 10-15 y).

Effective doses were derived using the following equation

$$
E=\sum_{T} W_{T}\left[\frac{H_{T}^{M}+H_{T}^{F}}{2}\right]
$$

where $H_{T}^{M}$ and $H_{T}^{F}$ are equivalent doses $\left(H_{T}=\right.$ $W_{R} \times D_{T}, W_{R}=1$ for photons) assessed for organ or tissue $T$ of the reference male and reference female, respectively. In this equation, breast and gonad doses from male and female phantoms were averaged. Moreover, since newborn, 1-year, 5-year, 10-year male and female phantoms have the identical anatomy with the exception of their gender - specific organs (prostate, uterus, testes, and ovaries), the $\mathrm{CTDI}_{\mathrm{vol}}$ - and $100 \mathrm{mAs}$ - normalized organ absorbed doses from only the male phantoms were used to compute doses to organs other than gender - specific organs. Note that the female phantoms would also have been used and would have provided the same results. The $\mathrm{CTDI}_{\mathrm{vol}}$ - and $100 \mathrm{mAs}$ - normalized organ absorbed doses for the gender - specific organs were obtained from separate male and female phantoms. For ages greater than 10, CTDI ${ }_{\text {vol }}$ - and 100 mAs - normalized organ absorbed doses for male and female phantoms were used and then averaged. ICRP publications 60 and 103 [7, 10] were respectively used in the calculations.

For comparison purposes, effective dose were also computed in this study through the use of DLP-toeffective dose conversion factors ( $k$-factors) by the following formula

$$
E=\frac{m A s}{100} \times k \times D L P
$$

where DLP is the dose - length product displayed on the console of the CT machine at a given $\mathrm{mAs}$ and $120 \mathrm{kV}_{\mathrm{p}}, k$ is the DLP-to-effective dose conversion factor determined at $100 \mathrm{mAs}$ and $120 \mathrm{kV}_{\mathrm{p}}$ and given in references $[9,11,12]$. Usually $k$ is given for newborn, 1-year, 5-year, 10-year and 15-year and linear interpolation was performed to calculate $k$ values for age values in between. A mean value was calculated for each age group considered in the study.

\section{RESULTS AND DISCUSSION}

\section{III.1-Patient population}

Patient demographics are presented in Table 2 and Figure 1. The minimum, mean $\pm 1 \sigma$ and maximum patient age were respectively 0.25 (3 months), $7.0 \pm$ 4.2 and 15.0 years. Patients of age $<1$ year and those of age > 10 represented about $4 \%$ and $37 \%$, respectively, of the population while patients of age between 1 and 10 years represented $59 \%$. The examinations with the highest and lowest frequencies are head (64\%) and Chest (8\%), respectively, while AP and CAP represented $18 \%$ and $10 \%$, respectively. Of the total data collected, the gender was reported only for $88 \%$ of all the cases, among which $41 \%$ were female patients and $59 \%$ were male patients.

\section{III.2-Estimation of organ and effective doses}

Using Equations 1 and 2, relevant tables of reference

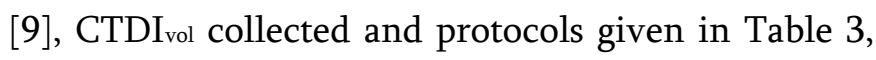
absorbed dose to 33 organ and effective doses ( $E_{60}$ and $E_{103}$, corresponding to the use of ICRP publication 60 and 103 tissue weighting factors, respectively) were estimated for each CT scan type and for different ages, using linear interpolation where appropriate. For head, chest, AP and CAP scans, mean values for the age group considered in the study $(<1 \mathrm{y}, 1-4 \mathrm{y}, 5-9 \mathrm{y}$ and $10-15$ y) were calculated. Results are summarized in Tables 4-10. For the calculation of effective dose using ICRP 60 tissue weighting factors, the brain was considered as part of the remainder tissues. In the 
case of head scan, as the brain received an equivalent dose in excess of the highest dose in any of the twelve organs for which a tissue weighting factor is specified, a weighting factor of 0.025 was applied to the brain and a weighting factor of 0.025 was applied to the average dose in the rest of the remainder tissues [10].

A relatively high variation in organ and effective doses was observed in each age group, certainly due to the dependence of patient dose on the practice of technicians who perform the CT scan within the same facility or from one facility to another, patient size and lack of adequate training of technicians. This variation is shown by the standard deviation in Tables 4-10.

In the case of head scan (Tables 4-5), brain, eye lens and red bone marrow received relatively high doses. The brain was delivered a mean dose of $138.73 \mathrm{mGy}$ (dose range: 69.07-224.54 mGy), $127.40 \mathrm{mGy}$ (dose range: 108.03-201.69 $\mathrm{mGy}$ ), $130.09 \mathrm{mGy}$ (dose range: 103.83-203.13 $\mathrm{mGy}$ ) and $132.80 \mathrm{mGy}$ (dose range: 98.97-202.67 mGy) for the age groups < 1 y, 1-4 y, 5-9 $\mathrm{y}$ and 10-15 y, respectively. When a contrast product was used, the brain received a mean dose of 420.36 mGy (dose range: 216.33-643.78 mGy), $301.25 \mathrm{mGy}$ (dose range: 208.69-406.27 $\mathrm{mGy}$ ) and $325.59 \mathrm{mGy}$ (dose range: 134.34-991.51 $\mathrm{mGy}$ ) for the age groups 1$4 \mathrm{y}, 5-9 \mathrm{y}$ and $10-15 \mathrm{y}$, respectively.

The red bone marrow was delivered a mean dose of $45.54 \mathrm{mGy}$ (dose range: 22.19-72.13 mGy), $48.59 \mathrm{mGy}$ (dose range: 40.40-74.89 mGy), $37.91 \mathrm{mGy}$ (dose range: $24.48-56.12 \mathrm{mGy}$ ) and $23.81 \mathrm{mGy}$ (dose range: 15.04-38.32 mGy) for the age groups < 1 y, 1-4 y, 5-9 $\mathrm{y}$ and $10-15 \mathrm{y}$, respectively. In the case where a contrast agent was used, the red bone marrow was delivered a mean dose of $157.79 \mathrm{mGy}$ (dose range: 79.29-246.08 mGy), 81.97 mGy (dose range: 48.98$109.14 \mathrm{mGy}$ ) and $57.42 \mathrm{mGy}$ (dose range: 25.57$150.69 \mathrm{mGy}$ ) for the age groups $1-4 \mathrm{y}, 5-9 \mathrm{y}$ and $10-15$ $\mathrm{y}$, respectively.

These relatively high brain and red bone marrow absorbed doses are of great concern as leukaemia and brain tumours are the most common childhood cancers [3].

The eye lens was delivered a mean dose of 140.65 mGy (dose range: 69.99-227.52 mGy), $132.69 \mathrm{mGy}$ (dose range: 114.63-209.74 mGy), 139.26 mGy (dose range: $110.79-215.73 \mathrm{mGy}$ ) and $148.86 \mathrm{mGy}$ (dose range: $110.05-231.62 \mathrm{mGy}$ ) for the age groups $<1 \mathrm{y}$, 1-4 y, 5-9 y and 10-15 y, respectively. When a contrast agent was used, the eye lens received a mean dose of 437.87 mGy (dose range: 224.97-673.81 mGy), $314.43 \mathrm{mGy}$ (dose range: 221.63-434.44 $\mathrm{mGy}$ ) and 367.27 mGy (dose range: 147.00-1176.71 $\mathrm{mGy}$ ) for the age groups 1-4 y, 5-9 y and 10-15 y, respectively. This is critical as the eye lens is one of the most radiosensitive tissues in the body for which detectable changes are noted at doses between $200 \mathrm{mGy}$ and 500 $\mathrm{mGy}$, the latter value being considered by ICRP as the threshold for absorbed dose to the eye lens for induction of cataract which is the main pathology of the lens and the leading cause of blindness worldwide [13].

For chest scan (Tables 6-7), the organs with the most elevated dose were salivary glands, thyroid, oesophagus, thymus, lungs, breast, stomach, liver, gall bladder, adrenals, spleen, pancreas, kidney and red bone marrow. The organs associated with the minimum and maximum mean dose were the kidney (8.01 mGy, range: $0.66-15.35 \mathrm{mGy}$ ) and the thyroid (29.85 $\mathrm{mGy}$, range: 2.51-57.20 $\mathrm{mGy}$ ) for the age group < $1 \mathrm{y}$; the kidney (3.82 $\mathrm{mGy}$, range: 1.51-8.44 mGy) and lungs (13.75 $\mathrm{mGy}$, range: 5.44-30.36 $\mathrm{mGy}$ ) for age group 1-4 y; the salivary glands $(3.65 \mathrm{mGy}$, range: 2.86-4.45 $\mathrm{mGy}$ ) and lungs (38.56 mGy, range: 35.85$41.26 \mathrm{mGy}$ ) for the age group 10-15 y. When a contrast product was used, the organs associated with the minimum and maximum mean dose were the salivary glands (3.20 mGy, range: $0.27-6.13 \mathrm{mGy}$ ) and the thyroid (39.08 $\mathrm{mGy}$, range: 10.68-67.49 $\mathrm{mGy}$ ) for the age group 5-9 y; the salivary glands $(6.28 \mathrm{mGy}$, range: 3.66-8.91 $\mathrm{mGy}$ ) and lungs $(62.15 \mathrm{mGy}$, range: 41.77-82.52 mGy) for the age group 10-15 $\mathrm{y}$. 
For AP scan (Tables 8-9), the organs with the most elevated dose were thyroid, oesophagus, thymus, lungs, breast, stomach, liver, gall bladder, adrenals, spleen, pancreas, kidney, prostate, uterus, gonads, colon, bladder and red bone marrow. The organs associated with the minimum and maximum mean dose were the thyroid (2.56 $\mathrm{mGy}$, range: 2.16-3.21 $\mathrm{mGy}$ ) and the kidney (53.84 $\mathrm{mGy}$, range: 52.99-55.12 $\mathrm{mGy}$ ) for the age group 1-4 y; the thyroid $(0.79 \mathrm{mGy}$, range: $0.47-0.89 \mathrm{mGy})$ and the kidney $(41.00 \mathrm{mGy}$, range: $24.54-45.73 \mathrm{mGy}$ ) for age group $10-15 \mathrm{y}$; In the case where a contrast agent was used, the organs associated with the minimum and maximum mean dose were the thyroid (5.33 $\mathrm{mGy}$, range: 4.31-6.00 $\mathrm{mGy}$ ) and the kidney (108.09 $\mathrm{mGy}$, range: 105.97$109.49 \mathrm{mGy}$ ) for the age group 1-4 y; the thyroid (1.32 $\mathrm{mGy}$, range: $0.99-1.48 \mathrm{mGy}$ ) and the kidney (69.86 $\mathrm{mGy}$, range: $50.69-76.67 \mathrm{mGy}$ ) for the age group $10-15 \mathrm{y}$.

For CAP scan (Table 10), the organs with the most elevated dose were salivary glands, thyroid, oesophagus, thymus, lungs, breast, stomach, liver, gall bladder, adrenals, spleen, pancreas, kidney, prostate, uterus, gonads, colon, bladder and red bone marrow. The organs associated with the minimum and maximum mean dose were salivary glands $(6.77 \mathrm{mGy}$, range: $5.20-8.16 \mathrm{mGy}$ ) and the kidney $(56.94 \mathrm{mGy}$, range: $55.10-59.84 \mathrm{mGy}$ ) for the age group 1-4 y; salivary glands (4.48 $\mathrm{mGy}$, range: $4.26-4.71 \mathrm{mGy}$ ) and the kidney (50.90 $\mathrm{mGy}$, range: 47.79-54.01 $\mathrm{mGy}$ ) for age group 5-9 y; salivary glands $(3.69 \mathrm{mGy}$, range: 2.59-4.61 $\mathrm{mGy}$ ) and the kidney $(40.70 \mathrm{mGy}$, range: 30.36-47.32 mGy) for age group 10-15 y; Only a twoyears old patient underwent a CAP scan with the use of a contrast agent (Figure 8). For this case, the salivary glands and the kidney were delivered absorbed doses of $14.26 \mathrm{mGy}$ and $114.38 \mathrm{mGy}$, respectively.

\section{IV.DISCUSSION}

Comparison with other studies has shown significant difference in absorbed dose values with those estimated in this study. Gao et al. [14] who estimated organ and effective doses from CT scans of paediatric oncologic patients (age groups: < $1 \mathrm{y}, 1-5 \mathrm{y}, 6-10 \mathrm{y}$ and 11-15 y; routine CT scans with or without imaging contrast were selected) using patient-specific information at a large academic cancer centre (USA), found, for head CT scan, maximum brain, red bone marrow, eye lens, salivary glands and thyroid mean doses of $48.7 \mathrm{mGy}, 15.6 \mathrm{mGy}, 68.6 \mathrm{mGy}, 34.3 \mathrm{mGy}$ and $5.6 \mathrm{mGy}$, respectively. For chest CT scan, the maximum thyroid, breast, lung and stomach mean doses were, respectively, 7.3 mGy, 7.7 mGy, 9.5 mGy and $5.1 \mathrm{mGy}$. The maximum mean doses estimated for lungs, breast, liver, gonads, stomach, colon and bladder were $5.7 \mathrm{mGy}, 9.1 \mathrm{mGy}, 16.1 \mathrm{mGy}, 21.4 \mathrm{mGy}$, $15.8 \mathrm{mGy}, 17.7 \mathrm{mGy}$ and $17.6 \mathrm{mGy}$, respectively, for AP scan. In the case of CAP CT scan, the maximum thyroid, lungs, liver, gonads, stomach, colon, bladder mean doses were $9.4 \mathrm{mGy}, 15.2 \mathrm{mGy}, 18.9 \mathrm{mGy}, 22.0$ mGy, $18.1 \mathrm{mGy}, \quad 18.8 \mathrm{mGy}$ and $17.9 \mathrm{mGy}$. Tahmasebzadeh et al [15] evaluated organ doses in paediatric patients (age groups: < 1 y, 1-4 y, 5-9 y and 10-15 y) who underwent CT scans (among which contrast agents were used in $18.8 \%$ of the cases) in five paediatric medical imaging centers located in Teheran province, Iran. In the case of multiphase examinations, organ doses were calculated for each phase and the total dose was used in subsequent estimation. They found, for head scan, maximum brain, eye lens, active bone marrow, and thyroid median doses of $17.6 \mathrm{mGy}, 18.9 \mathrm{mGy}, 5.5 \mathrm{mGy}$ and $5.4 \mathrm{mGy}$, respectively. For chest scan, the maximum thyroid, oesophagus, breast and lung median doses were $11.5 \mathrm{mGy}, 7.3 \mathrm{mGy}, 5.4 \mathrm{mGy}$ and $7.9 \mathrm{mGy}$, respectively. For AP scan, the maximum median doses estimated for stomach, colon, pancreas, liver, kidney, active bone marrow and urinary bladder were $15.5 \mathrm{mGy}, 17.6 \mathrm{mGy}, 15.1 \mathrm{mGy}, 14.6 \mathrm{mGy}, 15.6 \mathrm{mGy}$, $5.7 \mathrm{mGy}$ and $14.4 \mathrm{mGy}$, respectively. Etani,et al [16] 
estimated organ doses from data on actual patient information and CT scan parameters collected from hospitals and medical facilities with more than 200 beds that perform paediatric CT in the Kyushu region, Japan. They divided the paediatric population into five age groups - 0 y, 1 y, 5 y, 10 y and $15 \mathrm{y}$ - based on body size. Their study, which focused on head CT scan, did not mentioned whether multiphase CT examinations were included in the study. They found maximum brain, eye lens, bone marrow and thyroid mean doses of $54.9 \mathrm{mGy}, 52.0 \mathrm{mGy}, 14.0 \mathrm{mGy}$ and 4.2 $\mathrm{mGy}$.

Regarding effective dose estimation (Tables 4-10), the examination with the highest value, $62.90 \mathrm{mSv}$ (age group 1-4 y, use of a contrast agent), was AP scan, followed by CAP scan, $42.85 \mathrm{mSv}$ (age group 1-4 y; the two-years old patient who underwent a CAP scan with the use of a contrast agent received an effective dose of $85.15 \mathrm{mSv}$ ), head scan, $39.54 \mathrm{mSv}$ (age group 1-4 y, use of a contrast agent) and chest scan, 26.53 $\mathrm{mSv}$ (age group 10-15 y, use of a contrast product).

Effective doses derived from MC calculations and ICRP publications 60 and 103 tissues weighting factors (E60 and $\left.E_{103}\right)$ showed a $0.40-17.61 \%$ difference.

Finally, effective doses were also computed in this study through the use of DLP-to-effective dose conversion factors ( $E_{60-N C I}$ and $E_{103-N C I}, E_{60-S h r}, E_{60-P a u l}$ and $E_{103-P a u l}$, taken from references [9, 11, 12], respectively. Figures 2 to 8 compares effective doses computed using Equation 2 and those calculated using Equation 3. It is observed that effective doses computed through $k$-factors do not, in general, underestimate values derived from MC calculations, except for E60-Paul and E103-Paul in the case of head scan. Also, it is observed that the use of $k$-factors is not appropriate for paediatric patients of age $<1 \mathrm{y}$ as this leads to large overestimations of effective dose values (Figures 2, 4). It is also shown that E60-Paul and E103-Paul underestimate effective dose values (except for $<1$ y) in the case of head scan and provide the highest overestimation of effective dose values in the case of chest scan, up to $\approx 225 \%$ (Figures 2-5). If one excludes the age group $<1 \mathrm{y}$ and $E_{60-P a u l}$ and $E_{103-P a u l}$, the difference between effective doses derived by MC and $k$-factors is $0.06-26 \%, 4.0-81 \%, 26-64 \%$, and 0.6-17\% for head, chest, AP and CAP scans, respectively. It is seen that the use of $k$ - factors to derive effective dose may lead to values different from the "actual" values up to $\approx 225 \%$. This might be due to the phantom used to derive DLP-to-effective dose conversion factors. For instance, Shrimpton [11] used Cristy and Eckerman mathematical phantom series [20] with some changes regarding thyroid, heart, oesophagus and trunk. Deak and al. [12] used a modified Cristy and Eckerman phantom series to include the new organs and tissues introduced by ICRP publication 103 while Lee et al. [9] used reference paediatric voxel phantoms. Another reason might be the scan length. Deak et al. used a $32 \mathrm{~cm}$ CTDI phantom for body phantom whereas Lee et al used both $16 \mathrm{~cm}$ - and $32 \mathrm{~cm}$-CTDI phantoms.

It has been observed in this study that just multiplying $k$-factors by DLPs may lead to serious underestimation of effective dose. It is necessary to use correction factors for $\mathrm{mAs}$ and $\mathrm{kVp}$ as it was done in this study explicitly and implicitly, respectively (Equation 3). Other CT machine parameters, such as helical pitch, or actual patient scan length correction factors may be of significant importance to help reduce the difference in effective dose values computed by $k$-factors and those calculated by MC methods.

Table 11 shows comparison between effective doses determined in this study and those estimated in other studies. One can clearly see that values obtained in this study are largely greater than those determined in these studies.

The present study describes the current practice in three hospitals in Brazzaville, Congo Republic. No information or advice on dose reduction strategies were provided to technologists performing CT scans 
before that the study be undertaken. This will allow a comparison of the present study to subsequent studies after dose reduction techniques will be applied in those hospitals. The authors have decided to publish the results of this study mainly to raise awareness of the country decision-makers but also to demonstrate the fact that although equipment manufacturers regularly make progress towards automating CT dose optimization, dose reduction techniques rely essentially on technologists.

Results of the present study have shown that doses to paediatric patients are largely higher than those found in the literature. Although limitation of doses does not apply to medical exposure, the doses determined in this study are unacceptable. Therefore, urgent steps should be taken in order to reduce doses to paediatric patients to levels observed in countries where dose reduction techniques are successfully applied. The lack of a fully established regulatory authority, whose main responsibilities are regulations establishment, authorization, inspection and enforcement, plays an important part to the situation observed in this study. For now, only some activities, including authorization and management of radioactive sources, are regulated by the ministry of mines.

The following are dose reduction techniques that can easily be put in place given the context that the study has highlighted. The first step in the strategy of minimizing radiation dose to paediatric patients while maximizing diagnostic information is to ensure that each CT scan performed is medically justified. It is now generally accepted that approximately $30 \%$ of all CT scans could be avoided altogether or replaced by a different diagnostic tool [21]. Appropriate knowledge and awareness of the referring providers of the amount of radiation exposure and potential risk of inducing fatal cancer from each of the commonly performed diagnostic CT scan should be provided. Once individual CT scan is justified, radiologists, technologists and medical physicists should accept the primary responsibility for minimizing radiation dose to patients from CT. From the observation of the $\mathrm{CTDI}_{\text {vol }}$ or DLP values on the CT console just before the patient is scanned, radiologists or technologists may modify this CTDI vol or DLP values if deemed excessive for a particular examination. To do so, dose reduction techniques may be followed.

The first dose reduction technique is to adjust properly relevant CT parameters. Lowering tube current or tube voltage $\left(\mathrm{kV}_{\mathrm{p}}\right)$ is the most direct way of achieving radiation dose reduction [22]. Radiation dose is directly proportional to the $\mathrm{mAs}$, the tube current-time product, if all other factors are held constant [23]. This means that if the $\mathrm{mAs}$ for a particular CT examination is reduced by $50 \%$, the radiation dose is also reduced by $50 \%$. If all other parameters are held constant, radiation dose can be reduced by lowering the tube current $(\mathrm{mA})$ or decreasing the $\mathrm{x}$-ray tube rotation time. Because the tube current is easier to modify and the result is more predictable, modification of the tube current is most widely used. However, image noise is proportional to $1 / \sqrt{m A s}$, meaning that lowering $\mathrm{mAs}$ increases image noise. The relationship of dose to $\mathrm{kV}_{\mathrm{p}}$ is of the form dose $=a \times\left(k V_{p}\right)^{n}$ with $n$ ranging from 2.5 to 3.1 and $a$ a constant $[23,24]$. For a typical CT scan of the abdomen, decreasing the tube voltage from 140 to 120 $\mathrm{kV}_{\mathrm{p}}$ reduces the dose by 28 to $40 \%$. The dose is further decreased by about $65 \%$ if the tube voltage is decreased to $80 \mathrm{kV}_{\mathrm{p}}$. However, tube voltage changes are limited since users can select from only some preset peak kilovoltage settings. Furthermore, decreasing the $\mathrm{kV}_{\mathrm{p}}$ setting will also increase image noise as image noise is proportional to $1 / \sqrt{\text { dose }}$ (as the dose is directly proportional to the $\mathrm{mAs}$ ). To compensate for the increased noise, the mAs must be increased. This "low-tube voltage, high-tube current" strategy is efficient for small and average-sized patients. For large patients, since lowering the $\mathrm{kV}_{\mathrm{p}}$ results in increased noise that may not be overcome by increasing the tube-current, a higher tube-voltage may be the most dose efficient strategy because the shallow dose due to $\mathrm{x}$-rays of low-energy will be 
avoided. Janet et al. [24] established an optimization curve technique to determine optimal $\mathrm{mAs}$ and $\mathrm{kV}_{\mathrm{p}}$ pairs for patient abdominal circumference: $80 \mathrm{kV}_{\mathrm{p}}$ and $100 \mathrm{mAs}$ for the smallest patients $(30-60 \mathrm{~cm}$ equivalent abdominal circumference), $100 \mathrm{kV}_{\mathrm{p}}$ and 60 $\mathrm{mAs}$ for $60-70 \mathrm{~cm}$ equivalent abdominal circumference, and $120 \mathrm{kV}_{\mathrm{p}}$ and $60 \mathrm{mAs}$ for 75-100 $\mathrm{cm}$ equivalent abdominal circumference.

Automatic exposure control is also a useful technique to reduce patient dose by essentially providing a programmed dynamic adjustment of the tube current to achieve consistent image quality between patients [22]. This technology can reduce radiation dose by $20-44 \%$ when the appropriate image quality setting is chosen [23]. However, identifying the optimal image quality settings is not straightforward. Usually, scan projection radiographs are obtained in one or two projections to estimate the attenuation value of the patient, which is used to adjust the tube current. However, it should be ensured that the radiation dose associated with the scan projection radiographs is negligible compared to the amount of radiation dose to be reduced. Because image noise is also dependent on patient size, for CT scan to maintain a constant noise level, going from small to large patients, the mAs setting would have to be increased exponentially, resulting in dose reduction in CT scans for thin and average-sized patients, and an increased radiation dose in obese patients to avoid to obtain poor image quality for the latter.

There are other factors than CT machine parameters involved in patient dose reduction. Patient size is critical in the design of body CT protocols because of its effects on noise tolerance, radiation sensitivity and optimal $\mathrm{kV}_{\mathrm{p}}$ and $\mathrm{mAs}$ requirements [23]. CT technical parameters (e.g. $k V_{p}, m A s$, etc.) must be adjusted according to patient size (patient weight, body mass index, abdominal circumference, etc.). Another strategy is to reduce the number of multiple phase scans (e.g. pre-contrast) with contrast material unless medically justified. In this study, examinations with contrast are in fact double-phase examinations, the first phase being performed without contrast and the second with contrast. As shown in the study, multiphase scans significantly increase the dose to an organ, and most reported overdose events have been the result of multiphase scans [25]. The use of multiphase CT scanning in children should be limited to the absolute necessity. Bismuth shields may also be used to cast a shadow and reduce the radiation dose to the underlying structure (mainly breast, eyes and thyroid) while maintaining image quality elsewhere. Clinical studies have shown a $29 \%$ decrease in radiation dose to the paediatric female breast [6]. Bismuth shields may create a significant financial cost in a high-volume practice as they are sold as singleused items. A solution is to wrap them in a sheet or blanket to prevent skin contact so that they can be reused.

Medical personnel involved in radiological imaging should be trained appropriately about the potential hazards of medical radiation, and in order to be familiar with the variety of methods and techniques for patient radiation dose reduction. The latter requires a team approach involving the radiologist, the technologist and the medical physicist. The radiologist should be responsible for ensuring that every CT scan in paediatric patients is thoughtful, appropriate and medically justified for that particular child. The technologist should be responsible for ensuring that protocols are adjusted to use child-size parameters and verifying that proper scan technique factors are set for each paediatric scan. The medical physicist, if available, should be responsible for improving image quality by providing guidance on appropriate paediatric techniques [25].

\section{v. CONCLUSION}

The present study aimed at estimating organ and effective doses from CT scans of paediatric patients in three hospitals in Brazzaville, Congo Republic. It has been shown that doses values determined are largely 
higher that those found in the literature. In the particular case of head scan, brain, eye lens and red bone marrow received relatively high doses. This is a serious concern as leukaemia and brain tumours are the most common childhood cancers. In some cases, eye lens dose exceeded the absorbed dose threshold of $500 \mathrm{mGy}$ for induction of cataract which is a delayed deterministic effect and the main pathology of eye lens.

Effective doses derived from MC calculations and ICRP publications 60 and 103 tissues weighting factors showed a relatively small difference. It has been shown that effective doses derived by the use of $k$ - factors may lead to values significantly different from those obtained by MC calculation.

The study has also shown that although limitation of doses does not apply to medical exposure, the doses determined were unacceptable.

Finally, strategies for minimizing radiation dose to paediatric patients while maximizing diagnostic information should be urgently put in place and applied in the hospitals involved in the study among which the justification of each CT scan to be performed, lowering tube current and / or tube voltage, automatic exposure control, patient size, reduction of the number of multiple phase scans, use of bismuth shields and appropriate training of the medical personnel involved in radiological imaging.

\section{REFERENCES}

[1]. International Atomic Energy Agency. Radiation Protection and Safety in Medical Uses of Ionizing Radiation. Specific Safety Guide No. SSG-46. IAEA (2018).

[2]. United Nations Scientific Committee on the Effects of Atomic Radiation. Sources and Effects of Ionizing Radiation. UNSCEAR 2008 Report to the General Assembly with Scientific Annexes. UNSCEAR (2010).
[3]. International Atomic Energy Agency. Dosimetry in Diagnostic Radiology for Paediatric Patients. IAEA Human Health Series No. 24. IAEA (2018).

[4]. Maldjian P. D., Goldman A. R. Reducing Radiation Dose in Body CT: A Primer on Dose Metrics and Key CT Technical Parameters. AJR 200, 741-747 (2013).

[5]. Huda W., Ogden K. M., Khorasani M. R. Converting Dose-Length Product to Effective Dose at CT. Radiology 248, 995-1003 (2008).

[6]. Coakley F. V., Gould R., Yeh B. M., Arenson R. L. CT Radiation Dose: What Can You Do Right Now in Your Practice? AJR 196, 619-625 (2011).

[7]. International Commission on Radiological Protection. The 2007 Recommendations of the International Commission on Radiological Protection. Annals of the ICRP. ICRP Publication 103. ICRP (2007).

[8]. Moore B. M., Brady S. L., Mirro A. E., Kaufman R. A. Sized-Specific Dose Estimates (SSDE) provides a Simple Method to Calculate Organ Dose for Pediatric CT Examinations. Med. Phys. 41 (7), 071917-1-10 (2014).

[9]. Lee C., Kim K. P, Long D. J., Bolch W. E. Organ Doses for Reference Pediatric and Adolescent Patient Undergoing Computed Tomography Estimated by Monte Carlo Simulation. Med. Phys. 39 (34), 2129-2146 (2012).

[10]. International Commission on Radiological Protection. 1990 Recommendations of the International Commission on Radiological Protection. Annals of the ICRP. ICRP Publication 60. ICRP (1991).

[11]. Shrimpton P. C. Assessment of Patient Dose in CT. National Radiation Protection Board report No. NRPB-PE/1/2004. NRPB (2004).

[12]. Deak P. D, Smal Y., Kalender W. A. Multisection CT Protocols: Sex- and AgeSpecific Conversion Factors Used to Determine 
Effective Dose from Dose-Length Product. Radiology 257, 158-166 (2010).

[13]. International Commission on Radiological Protection. ICRP Statement on Tissue Reactions and Early and Late Effects of Radiation in Normal Tissue and Organs - Threshold Doses for Tissue Reactions in a Radiation Protection Context. ICRP Publication 118. ICRP (2012).

[14]. Gao Y., Quinn B., Pandit-Taskar N. et al. Patient-Specific Organ and Effective Dose Estimates in Pediatric Oncology Computed Tomography. Physica Medica 45, 146-155 (2018).

[15]. Tahmasebzadeh A., Paydar R., Soltanikermanshahi M., Maziar A., Reiazi R. Lifetime Attributable Cancer Risk Related to Prevalent CT Scan Procedures in Paediatric Medical Imaging Centers. International Journal of Radiation Biology, 1-8 (2021).

[16]. Etani R., Yoshitake T., Kai M. Estimating Organ Doses from Paediatric Cerebral Computed Tomography Using the WAZA-ARI Web-Based Calculator. Journal of Radiation Protection and Research 46 (1), 1-7 (2021).

[17]. Hwang J. Y, Do K. H., Yang D. H. et al. A Survey of Pediatric CT Protocols and Radiation Doses in South Korean Hospitals to optimize the Radiation Dose for pediatric CT scanning. Medicine, 94 (50):e2146 (2015).

[18]. Galanski M., Nagel H. D., Stamm G. Results of a Federation Inquiry 2005/2006: Pediatric CT XRay Practice in Germany. Rofo 179, 1110-1111 (2007).

[19]. Muhammad N.A., Karim M. K. A. et al. Diagnostic Reference level of Radiation Dose and Image Quality among Paediatric CT examinations in a Tertiary Hospital in Malaysia. Diagnostics 10 (8): 591(2020).
[20]. Cristy M., Eckerman K. F. Specific Absorbed fractions of energy at various ages from internal photon sources. I. Methods. Report No. ORNL5000. ORNL (1974).

[21]. Puri S., Hu R., Quazi R. R. et al. Physician' and Midlevel Providers' Awareness of Lifetime Radiation - Attributable Cancer Risk Associated with Commonly Performed CT Studies: Relationship to Practice Behavior. AJR 199, 1328-1336 (2012).

[22]. Kubo T., Li P. J. P., Stiller W. et al. Radiation Dose Reduction in Chest CT: A Review. AJR 190, 335-343 (2008).

[23]. Maldjian P. D., Goldman A. R. Reducing Radiation Dose in Body CT: A Primer on Dose Metrics and Key CT Technical Parameters. AJR 200, 741-747 (2013).

[24]. Reid J., Gamberoni J., Dong F., Davros W. Optimization of $\mathrm{kVp}$ and $\mathrm{mAs}$ for Pediatric Low-Dose Simulated Abdominal CT: Is it Best to Base Parameter Selection on Object Circumference? AJR 195, 1015-1020 (2010).

[25]. Nelson T. R. Practical Strategies to Reduce Pediatric CT Radiation Dose. J Am Coll Radiol 11, 292-299 (2014).

\section{Cite this article as :}

J. Bazoma, G. B. Dallou, P. Ondo Meye, C. Bouka Biona, Saïdou, G. H. Ben-Bolie, "Assessment of Organ and Effective Doses Received by Paediatric Patients Undergoing Computed Tomography Examinations in Three Hospitals in Brazzaville, Congo Republic: An Urgent Necessity for Regulatory Control", International Journal of Scientific Research in Science and Technology (IJSRST), Online ISSN : 2395-602X, Print ISSN : 2395-6011, Volume 8 Issue 5, pp. 527-537, September-October 2021. Available at doi : https://doi.org/10.32628/IJSRST218582 Journal URL : https://ijsrst.com/IJSRST218582 
Table 1: CT machines involved in the study.

Computed tomography facility

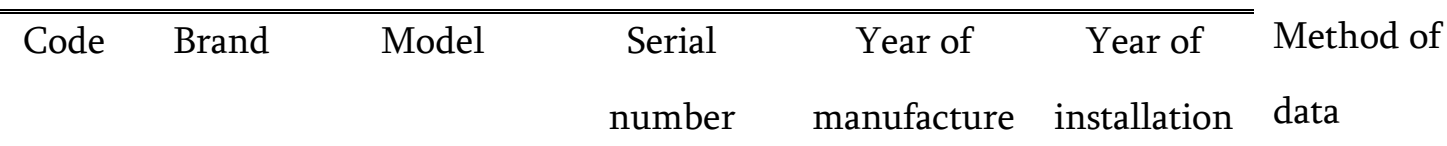

collection

\begin{tabular}{ccccccc}
\hline \hline A & Toshiba & Activion 16 & 1CA0882216 & 2008 & 2008 & Manually \\
B & Toshiba & Activion 16 & 1CA0882217 & 2008 & 2008 & Manually \\
C & Neusoft & NeuViz 16 & N16E150005 & 2015 & 2018 & Manually \\
\hline \hline
\end{tabular}

Table 2: Patient demographics.

\begin{tabular}{ccccccc}
\hline \hline & \multicolumn{5}{c}{ Number of patients } & Age (year) \\
\cline { 2 - 6 } Age group (year) & Head & Chest & AP $^{\dagger}$ & CAP $^{\ddagger}$ & Subtotal & Mean (Range) \\
\hline \hline$<1$ & 3 & 2 & - & - & 5 & $0.33(0.25-0.50)$ \\
{$[1,5[$} & 24 & 3 & 13 & 7 & 47 & $2.7(1.0-4.0)$ \\
{$[5,10[$} & 27 & 4 & 1 & 2 & 34 & $7.0(5.0-9.0)$ \\
{$[10,15]$} & 33 & 2 & 11 & 4 & 50 & $11.6(10.0-15.0)$ \\
\hline \hline Total & 87 & 11 & 25 & 13 & 136 & \\
\hline \hline
\end{tabular}

${ }^{\dagger}$ Abdomen-Pelvis.

‡ Chest-Abdomen-Pelvis.

Table 3: Protocols for different CT examinations used in hospitals involved in the study.

\begin{tabular}{ccc|cc}
\hline \hline & \multicolumn{3}{c}{ Type of CT machine } \\
\hline \hline & \multicolumn{2}{c}{ Toshiba Activion 16 } & \multicolumn{2}{c}{ Neusoft Neuviz 16 } \\
\cline { 2 - 5 } CT scan & $\mathrm{kVp}$ & $\mathrm{mAs}$ & $\mathrm{kVp}$ & $\mathrm{mAs}$ \\
\hline \hline Head & 120 & 250 & 120 & 280 \\
Chest & 120 & 150 & 120 & 250 \\
$\mathrm{AP}^{\dagger}$ & 120 & 187 & 120 & 250 \\
$\mathrm{CAP}^{\ddagger}$ & 120 & 150 & 120 & 250 \\
\hline \hline
\end{tabular}

${ }^{\dagger}$ Abdomen-Pelvis.

‡ Chest-Abdomen-Pelvis.

Table 4: Organ dose (mean $\pm 1 \sigma$, mGy) and effective dose (mean $\pm 1 \sigma$, mSv) derived from organ and tissue weighting factors from ICRP publications $60\left(E_{60}\right)$ and $103\left(E_{103}\right)$ for head scan without contrast.

\begin{tabular}{lcccc}
\hline \hline $\begin{array}{l}\text { Head scan without } \\
\text { contrast }\end{array}$ & $<1 \mathrm{y}$ & $1-4 \mathrm{y}$ & $5-9 \mathrm{y}$ & $10-15 \mathrm{y}$ \\
\hline \hline organ or tissue & & & & \\
\hline \hline Brain & $138.73 \pm$ & $127.40 \pm 35.06$ & $130.09 \pm 40.21$ & $132.80 \pm 45.37$ \\
& 78.99 & & & \\
Pituitary gland & $126.87 \pm$ & $113.95 \pm 31.29$ & $119.73 \pm 36.85$ & $123.07 \pm 42.15$ \\
& 72.70 & & & \\
\hline
\end{tabular}




\begin{tabular}{lcccc}
\hline Lens & $140.65 \pm$ & $132.69 \pm 36.49$ & $139.26 \pm 42.74$ & $148.86 \pm 51.69$ \\
& 80.01 & & & \\
Eye balls & $139.46 \pm$ & $136.43 \pm 36.75$ & $140.52 \pm 43.29$ & $147.90 \pm 51.00$ \\
Salivary glands & 78.63 & & & \\
Oral cavity & $75.26 \pm 42.90$ & $87.98 \pm 28.30$ & $87.98 \pm 28.30$ & $116.99 \pm 40.96$ \\
Spinal cord & $71.97 \pm 37.81$ & $110.68 \pm 30.85$ & $116.06 \pm 35.09$ & $107.12 \pm 36.19$ \\
Thyroid & $7.40 \pm 4.06$ & $9.52 \pm 2.88$ & $8.25 \pm 2.06$ & $11.59 \pm 5.87$ \\
Oesophagus & $21.67 \pm 12.65$ & $16.46 \pm 4.50$ & $28.80 \pm 14.98$ & $11.91 \pm 4.04$ \\
Trachea & $8.71 \pm 4.63$ & $10.36 \pm 2.88$ & $26.86 \pm 6.82$ & $4.37 \pm 1.49$ \\
Thymus & $11.86 \pm 6.37$ & $12.94 \pm 3.14$ & $2.12 \pm 0.54$ & $6.53 \pm 2.22$ \\
Lungs & $7.79 \pm 4.41$ & $6.71 \pm 1.84$ & $5.17 \pm 1.46$ & $4.18 \pm 1.41$ \\
Breast & $5.13 \pm 2.93$ & $4.72 \pm 1.30$ & $3.91 \pm 1.03$ & $2.39 \pm 0.81$ \\
Heart wall & $2.53 \pm 1.49$ & $1.61 \pm 0.44$ & $1.11 \pm 0.30$ & $0.66 \pm 0.23$ \\
Stomach wall & $4.22 \pm 2.43$ & $3.09 \pm 0.75$ & $2.62 \pm 1.45$ & $1.38 \pm 0.47$ \\
Liver & $1.42 \pm 0.82$ & $1.01 \pm 0.25$ & $0.87 \pm 0.49$ & $0.07 \pm 0.11$ \\
Gall Bladder & $1.84 \pm 1.08$ & $1.18 \pm 0.33$ & $0.72 \pm 0.19$ & $0.40 \pm 0.14$ \\
Adrenals & $0.92 \pm 0.52$ & $0.67 \pm 0.19$ & $0.39 \pm 0.11$ & $0.26 \pm 0.09$ \\
Spleen & $1.65 \pm 0.93$ & $1.34 \pm 0.39$ & $0.72 \pm 0.19$ & $0.36 \pm 0.13$ \\
Pancreas & $1.93 \pm 1.11$ & $1.34 \pm 0.39$ & $0.72 \pm 0.19$ & $0.40 \pm 0.14$ \\
Kidney & $1.15 \pm 0.69$ & $0.59 \pm 0.16$ & $0.33 \pm 0.09$ & $0.16 \pm 0.06$ \\
Small intestine wall & $1.05 \pm 0.60$ & $0.81 \pm 0.23$ & $0.48 \pm 0.13$ & $0.26 \pm 0.09$ \\
Colon wall & $0.55 \pm 0.34$ & $0.22 \pm 0.05$ & $0.08 \pm 0.03$ & $0 \pm 0$ \\
Rectosigmoid wall & $0.65 \pm 0.40$ & $0.22 \pm 0.05$ & $0.15 \pm 0.05$ & $0.10 \pm 0.04$ \\
Urinary bladder wall & $0.42 \pm 0.26$ & $0.14 \pm 0.04$ & $0.08 \pm 0.03$ & $0 \pm 0$ \\
Prostate & $0.23 \pm 0.14$ & $0.09 \pm 0.03$ & $0 \pm 0$ & $0 \pm 0$ \\
Uterus & $0.14 \pm 0.08$ & $0.08 \pm 0.04$ & $0 \pm 0$ & $0 \pm 0$ \\
Gonads & $0.23 \pm 0.14$ & $0.14 \pm 0.04$ & $0.09 \pm 0.03$ & $0 \pm 0$ \\
Skin & $0.18 \pm 0.11$ & $0.09 \pm 0.03$ & $0 \pm 0$ & $0 \pm 0$ \\
Muscle & $29.38 \pm 16.74$ & $24.39 \pm 6.67$ & $18.49 \pm 5.10$ & $14.03 \pm 4.74$ \\
Active marrow & $6.48 \pm 3.90$ & $3.51 \pm 1.04$ & $2.38 \pm 0.76$ & $2.48 \pm 0.84$ \\
Shallow marrow & $45.54 \pm 25.13$ & $48.59 \pm 12.55$ & $37.91 \pm 9.59$ & $23.81 \pm 8.07$ \\
E6o & $59.38 \pm 35.23$ & $41.07 \pm 11.13$ & $35.96 \pm 9.42$ & $26.76 \pm 9.05$ \\
E103 & $12.53 \pm 7.05$ & $12.14 \pm 3.25$ & $10.11 \pm 2.72$ & $7.78 \pm 2.63$ \\
\hline \hline & $10.65 \pm 5.95$ & $11.02 \pm 2.96$ & $9.21 \pm 2.44$ & $6.75 \pm 2.90$ \\
\hline
\end{tabular}

Table 5: Organ dose (mean $\pm 1 \sigma$, mGy) and effective dose (mean $\pm 1 \sigma, \mathrm{mSv}$ ) derived from organ and tissue weighting factors from ICRP publications $60\left(E_{60}\right)$ and $103\left(E_{103}\right)$ for head scan with contrast.

\begin{tabular}{|c|c|c|c|c|}
\hline $\begin{array}{l}\text { Head scan with } \\
\text { contrast }\end{array}$ & & & & \\
\hline organ or tissue & $<1 \mathrm{y}$ & $1-4 y$ & $5-9 y$ & $10-15 y$ \\
\hline
\end{tabular}




\begin{tabular}{|c|c|c|c|c|}
\hline Brain & --- & $\begin{array}{c}420.36 \pm \\
188.71\end{array}$ & $301.25 \pm 88.93$ & $325.59 \pm 265.69$ \\
\hline Pituitary gland & --- & $\begin{array}{c}375.92 \pm \\
168.95\end{array}$ & $270.46 \pm 81.42$ & $302.07 \pm 249.20$ \\
\hline Lens & --- & $\begin{array}{c}437.87 \pm \\
196.83\end{array}$ & $314.43 \pm 94.31$ & $367.27 \pm 318.46$ \\
\hline Eye balls & --- & $\begin{array}{c}448.06 \pm \\
200.86\end{array}$ & $317.48 \pm 95.69$ & $364.03 \pm 308.51$ \\
\hline Salivary glands & --- & $\begin{array}{c}296.29 \pm \\
136.20\end{array}$ & $260.57 \pm 72.69$ & $289.38 \pm 257.02$ \\
\hline Oral cavity & --- & $\begin{array}{c}366.34 \pm \\
164.97\end{array}$ & $261.39 \pm 76.89$ & $259.95 \pm 191.76$ \\
\hline Spinal cord & --- & $32.04 \pm 14.61$ & $17.61 \pm 4.05$ & $30.45 \pm 43.15$ \\
\hline Thyroid & --- & $54.19 \pm 33.69$ & $34.36 \pm 9.06$ & $28.70 \pm 19.73$ \\
\hline Oesophagus & --- & $24.28 \pm 14.95$ & $15.45 \pm 3.54$ & $10.50 \pm 6.96$ \\
\hline Trachea & --- & $40.46 \pm 17.98$ & $19.77 \pm 4.93$ & $15.72 \pm 10.69$ \\
\hline Thymus & --- & $21.91 \pm 9.75$ & $11.82 \pm 3.00$ & $10.17 \pm 7.64$ \\
\hline Lungs & --- & $15.59 \pm 7.00$ & $8.82 \pm 1.94$ & $5.77 \pm 4.00$ \\
\hline Breast & --- & $5.24 \pm 2.33$ & $2.52 \pm 0.56$ & $1.57 \pm 0.99$ \\
\hline Heart wall & --- & $9.73 \pm 4.32$ & $4.61 \pm 1.09$ & $3.51 \pm 2.22$ \\
\hline Stomach wall & --- & $3.12 \pm 1.39$ & $1.18 \pm 0.28$ & $0.25 \pm 0.31$ \\
\hline Liver & --- & $3.83 \pm 1.70$ & $1.62 \pm 0.35$ & $0.94 \pm 0.60$ \\
\hline Gall Bladder & --- & $2.16 \pm 0.96$ & $0.90 \pm 0.22$ & $0.63 \pm 0.40$ \\
\hline Adrenals & --- & $4.33 \pm 1.91$ & $1.62 \pm 0.35$ & $0.86 \pm 0.49$ \\
\hline Spleen & --- & $4.33 \pm 1.91$ & $1.62 \pm 0.35$ & $0.94 \pm 0.60$ \\
\hline Pancreas & --- & $1.91 \pm 0.85$ & $0.72 \pm 0.15$ & $0.40 \pm 0.33$ \\
\hline Kidney & --- & $2.63 \pm 1.17$ & $1.08 \pm 0.23$ & $0.63 \pm 0.40$ \\
\hline Small intestine wall & --- & $0.66 \pm 0.30$ & $0.16 \pm 0.08$ & $0 \pm 0$ \\
\hline Colon wall & --- & $0.66 \pm 0.30$ & $0.35 \pm 0.11$ & $0.23 \pm 0.13$ \\
\hline Rectosigmoid wall & --- & $0.47 \pm 0.21$ & $0.16 \pm 0.08$ & $0 \pm 0$ \\
\hline Urinary bladder wall & --- & $0.25 \pm 0.11$ & $0 \pm 0$ & $0 \pm 0$ \\
\hline Prostate & --- & $0.25 \pm 0.11$ & $0 \pm 0$ & $0 \pm 0$ \\
\hline Uterus & --- & $0.47 \pm 0.21$ & $0.18 \pm 0.05$ & $0 \pm 0$ \\
\hline Gonads & --- & $0.25 \pm 0.11$ & $0 \pm 0$ & $0 \pm 0$ \\
\hline Skin & --- & $79.73 \pm 35.50$ & $42.14 \pm 10.25$ & $34.05 \pm 25.18$ \\
\hline Muscle & --- & $11.31 \pm 4.99$ & $5.53 \pm 1.71$ & $6.05 \pm 4.77$ \\
\hline Active marrow & --- & $157.79 \pm 70.38$ & $81.97 \pm 18.97$ & $57.42 \pm 39.79$ \\
\hline Shallow marrow & --- & $135.07 \pm 60.60$ & $78.67 \pm 19.03$ & $65.05 \pm 48.92$ \\
\hline$E_{60}$ & --- & $38.96 \pm 17.40$ & $22.33 \pm 5.55$ & $18.91 \pm 14.05$ \\
\hline$E_{103}$ & --- & $39.54 \pm 17.69$ & $23.22 \pm 5.76$ & $19.67 \pm 14.65$ \\
\hline
\end{tabular}


Table 6: Organ dose (mean $\pm 1 \sigma$, mGy) and effective dose (mean $\pm 1 \sigma$, mSv) derived from organ and tissue weighting factors from ICRP publications $60\left(E_{60}\right)$ and $103\left(E_{103}\right)$ for chest scan without contrast.

\begin{tabular}{|c|c|c|c|c|}
\hline $\begin{array}{l}\text { Chest scan without } \\
\text { contrast }\end{array}$ & & & & \\
\hline organ or tissue & $<1 \mathrm{y}$ & $1-4 \mathrm{y}$ & $5-9 y$ & $10-15 \mathrm{y}$ \\
\hline Brain & $1.1 \pm 1.41$ & $0.37 \pm 0.38$ & --- & $0.91 \pm 0.25$ \\
\hline Pituitary gland & $1.22 \pm 1.60$ & $0.40 \pm 0.42$ & --- & $0.70 \pm 0.19$ \\
\hline Lens & $1.06 \pm 1.39$ & $0.27 \pm 0.29$ & --- & $0.63 \pm 0.08$ \\
\hline Eye balls & $1.16 \pm 1.53$ & $0.29 \pm 0.30$ & --- & $0.60 \pm 0.13$ \\
\hline Salivary glands & $14.56 \pm 18.53$ & $1.98 \pm 2.07$ & --- & $3.6 \pm 1.13$ \\
\hline Oral cavity & $6.93 \pm 9.12$ & $1.28 \pm 1.34$ & --- & $2.76 \pm 0.15$ \\
\hline Spinal cord & $18.59 \pm 24.26$ & $7.19 \pm 7.52$ & --- & $\begin{array}{c}11.32 \pm \\
1.59\end{array}$ \\
\hline Thyroid & $29.85 \pm 24.83$ & $\begin{array}{c}13.49 \pm \\
14.11\end{array}$ & --- & $\begin{array}{c}34.86 \pm \\
5.70\end{array}$ \\
\hline Oesophagus & $38.68 \pm 32.15$ & $\begin{array}{c}11.02 \pm \\
11.53\end{array}$ & --- & $\begin{array}{c}30.13 \pm \\
3.15\end{array}$ \\
\hline Trachea & $26.01 \pm 33.82$ & $\begin{array}{c}12.44 \pm \\
13.02\end{array}$ & --- & $\begin{array}{c}34.22 \pm \\
2.26\end{array}$ \\
\hline Thymus & $26.80 \pm 34.78$ & $\begin{array}{c}12.90 \pm \\
13.50\end{array}$ & --- & $\begin{array}{c}37.30 \pm \\
2.88\end{array}$ \\
\hline Lungs & $28.41 \pm 36.87$ & $\begin{array}{c}13.75 \pm \\
14.38\end{array}$ & --- & $\begin{array}{c}38.56 \pm \\
3.83\end{array}$ \\
\hline Breast & $26.09 \pm 33.76$ & $\begin{array}{c}11.19 \pm \\
11.71\end{array}$ & --- & $\begin{array}{c}33.18 \pm \\
1.85\end{array}$ \\
\hline Heart wall & $29.24 \pm 38.03$ & $\begin{array}{c}13.89 \pm \\
14.53\end{array}$ & --- & $\begin{array}{c}40.45 \pm \\
2.90\end{array}$ \\
\hline Stomach wall & $20.07 \pm 26.24$ & $6.90 \pm 7.22$ & --- & $\begin{array}{c}14.79 \pm \\
0.63\end{array}$ \\
\hline Liver & $23.31 \pm 30.05$ & $8.52 \pm 8.91$ & --- & $\begin{array}{c}22.62 \pm \\
1.11\end{array}$ \\
\hline Gall Bladder & $17.63 \pm 22.50$ & $3.23 \pm 3.38$ & --- & $8.51 \pm 1.26$ \\
\hline Adrenals & $22.35 \pm 28.97$ & $\begin{array}{c}10.34 \pm \\
10.82\end{array}$ & --- & $\begin{array}{c}14.38 \pm \\
0.11\end{array}$ \\
\hline Spleen & $25.92 \pm 33.53$ & $\begin{array}{c}11.03 \pm \\
11.54\end{array}$ & --- & $\begin{array}{c}17.69 \pm \\
0.87\end{array}$ \\
\hline Pancreas & $14.23 \pm 18.13$ & $2.15 \pm 2.25$ & --- & $5.78 \pm 0.44$ \\
\hline Kidney & $8.01 \pm 10.39$ & $3.82 \pm 4.00$ & --- & $5.06 \pm 0.19$ \\
\hline Small intestine wall & $3.42 \pm 4.54$ & $0.80 \pm 0.83$ & --- & $1.39 \pm 0.00$ \\
\hline Colon wall & $6.66 \pm 8.91$ & $0.87 \pm 0.91$ & --- & $1.23 \pm 0.22$ \\
\hline Rectosigmoid wall & $1.34 \pm 1.79$ & $0.23 \pm 0.25$ & --- & $0.18 \pm 0.03$ \\
\hline Urinary bladder wall & $0.81 \pm 1.08$ & $0.21 \pm 0.22$ & --- & $0.10 \pm 0.00$ \\
\hline Prostate & $0.52 \pm 0.67$ & $0.10 \pm 0.11$ & --- & $0.05 \pm 0.00$ \\
\hline Uterus & $0.94 \pm 1.21$ & $0.21 \pm 0.22$ & --- & $0.13 \pm 0.03$ \\
\hline Gonads & $0.87 \pm 1.11$ & $0.17 \pm 0.18$ & --- & $0.07 \pm 0.00$ \\
\hline Skin & $8.81 \pm 11.35$ & $3.16 \pm 3.30$ & --- & $7.61 \pm 0.50$ \\
\hline
\end{tabular}




\begin{tabular}{lcccc}
\hline Muscle & $10.31 \pm 13.27$ & $3.57 \pm 3.74$ & --- & $6.94 \pm 0.50$ \\
Active marrow & $10.64 \pm 13.91$ & $4.55 \pm 4.76$ & --- & $9.54 \pm 0.71$ \\
Shallow marrow & $11.96 \pm 15.57$ & $5.76 \pm 6.03$ & --- & $10.31 \pm$ \\
& & & & 2.07 \\
$E_{60}$ & $14.09 \pm 18.33$ & $5.70 \pm 5.96$ & --- & $14.38 \pm$ \\
& & & & 1.12 \\
$E_{103}$ & $16.42 \pm 21.33$ & $6.62 \pm 6.92$ & --- & $16.95 \pm$ \\
& & & & 1.20 \\
\hline \hline
\end{tabular}

Table 7: Organ dose (mean $\pm 1 \sigma$, mGy) and effective dose (mean $\pm 1 \sigma, \mathrm{mSv}$ ) derived from organ and tissue weighting factors from ICRP publications $60\left(E_{60}\right)$ and $103\left(E_{103}\right)$ for chest scan with contrast.

\begin{tabular}{|c|c|c|c|c|}
\hline \multicolumn{5}{|l|}{$\begin{array}{l}\text { Chest scan with } \\
\text { contrast }\end{array}$} \\
\hline organ or tissue & $<1 \mathrm{y}$ & $1-4 \mathrm{y}$ & $5-9 y$ & $10-15 y$ \\
\hline Brain & $\begin{array}{l}-- \\
-\end{array}$ & $\begin{array}{l}-- \\
-\end{array}$ & $0.89 \pm 0.77$ & $1.55 \pm 0.89$ \\
\hline Pituitary gland & --- & --- & $0.57 \pm 0.54$ & $1.20 \pm 0.69$ \\
\hline Lens & --- & --- & $0.49 \pm 0.46$ & $1.03 \pm 0.50$ \\
\hline Eye balls & --- & --- & $0.53 \pm 0.51$ & $1.01 \pm 0.53$ \\
\hline Salivary glands & --- & --- & $3.20 \pm 4.15$ & $6.28 \pm 3.71$ \\
\hline Oral cavity & --- & --- & $2.51 \pm 2.51$ & $4.39 \pm 1.91$ \\
\hline Spinal cord & --- & --- & $17.63 \pm 19.56$ & $16.86 \pm 4.99$ \\
\hline Thyroid & --- & --- & $39.08 \pm 40.17$ & $57.33 \pm 28.92$ \\
\hline Oesophagus & --- & --- & $29.83 \pm 30.14$ & $48.64 \pm 22.73$ \\
\hline Trachea & --- & --- & $35.75 \pm 36.70$ & $54.58 \pm 24.13$ \\
\hline Thymus & --- & --- & $37.95 \pm 38.69$ & $59.70 \pm 26.82$ \\
\hline Lungs & --- & --- & $37.29 \pm 37.51$ & $62.15 \pm 28.82$ \\
\hline Breast & --- & --- & $31.38 \pm 31.61$ & $52.74 \pm 22.95$ \\
\hline Heart wall & --- & --- & $38.40 \pm 38.63$ & $64.63 \pm 28.80$ \\
\hline Stomach wall & --- & --- & $15.53 \pm 16.18$ & $18.32 \pm 2.07$ \\
\hline Liver & --- & --- & $20.07 \pm 19.96$ & $35.88 \pm 15.45$ \\
\hline Gall Bladder & --- & --- & $5.61 \pm 5.36$ & $12.65 \pm 3.66$ \\
\hline Adrenals & --- & --- & $18.08 \pm 19.31$ & $22.39 \pm 8.78$ \\
\hline Spleen & --- & --- & $19.02 \pm 19.91$ & $27.17 \pm 9.85$ \\
\hline Pancreas & --- & --- & $4.80 \pm 4.67$ & $9.24 \pm 4.14$ \\
\hline Kidney & --- & --- & $5.43 \pm 5.62$ & $8.00 \pm 3.38$ \\
\hline Small intestine wall & --- & --- & $1.20 \pm 1.19$ & $2.16 \pm 0.86$ \\
\hline Colon wall & --- & --- & $1.24 \pm 1.24$ & $2.03 \pm 1.05$ \\
\hline Rectosigmoid wall & --- & --- & $0.34 \pm 0.38$ & $0.29 \pm 0.15$ \\
\hline Urinary bladder wall & --- & --- & $0.23 \pm 0.26$ & $0.15 \pm 0.06$ \\
\hline Prostate & --- & --- & $0.11 \pm 0.13$ & $0.08 \pm 0.03$ \\
\hline Uterus & --- & --- & $0.27 \pm 0.30$ & $0.22 \pm 0.12$ \\
\hline Gonads & --- & --- & $0.21 \pm 0.24$ & $0.12 \pm 0.05$ \\
\hline
\end{tabular}




\begin{tabular}{lllcl}
\hline Skin & --- & --- & $7.24 \pm 7.29$ & $12.14 \pm 5.37$ \\
Muscle & --- & --- & $8.23 \pm 8.78$ & $10.57 \pm 3.66$ \\
Active marrow & --- & --- & $7.94 \pm 7.74$ & $15.26 \pm 6.83$ \\
Shallow marrow & --- & --- & $12.23 \pm 12.65$ & $17.15 \pm 9.05$ \\
$E_{60}$ & --- & --- & $14.19 \pm 14.37$ & $22.49 \pm 9.60$ \\
$E_{103}$ & --- & --- & $16.57 \pm 16.78$ & $25.53 \pm 11.29$ \\
\hline \hline
\end{tabular}

Table 8: Organ dose (mean $\pm 1 \sigma$, mGy) and effective dose (mean $\pm 1 \sigma$, mSv) derived from organ and tissue weighting factors from ICRP publications $60\left(E_{60}\right)$ and $103\left(E_{103}\right)$ for AP scan without contrast.

\begin{tabular}{|c|c|c|c|c|}
\hline $\begin{array}{l}\mathrm{AP}^{\dagger} \mathrm{scan} \text { without } \\
\text { contrast }\end{array}$ & \multirow[b]{2}{*}{$<1 \mathrm{y}$} & \multirow[b]{2}{*}{$1-4 y$} & \multirow[b]{2}{*}{$5-9 y$} & \multirow[b]{2}{*}{$10-15 y$} \\
\hline organ or tissue & & & & \\
\hline Brain & --- & $0.30 \pm 0.028$ & --- & $0.09 \pm 0.02$ \\
\hline Pituitary gland & --- & $0.23 \pm 0.03$ & --- & $0.08 \pm 0.02$ \\
\hline Lens & --- & $0.31 \pm 0.05$ & --- & $0.09 \pm 0.02$ \\
\hline Eye balls & --- & $0.28 \pm 0.03$ & --- & $0.08 \pm 0.02$ \\
\hline Salivary glands & --- & $0.96 \pm 0.18$ & --- & $0.29 \pm 0.06$ \\
\hline Oral cavity & --- & $0.79 \pm 0.10$ & --- & $0.26 \pm 0.05$ \\
\hline Spinal cord & --- & $26.84 \pm 0.88$ & --- & $16.57 \pm 3.40$ \\
\hline Thyroid & --- & $2.56 \pm 0.48$ & --- & $0.79 \pm 0.16$ \\
\hline Oesophagus & --- & $12.35 \pm 0.92$ & --- & $9.37 \pm 1.86$ \\
\hline Trachea & --- & $3.10 \pm 0.11$ & --- & $1.69 \pm 0.35$ \\
\hline Thymus & --- & $5.31 \pm 0.52$ & --- & $2.22 \pm 0.48$ \\
\hline Lungs & --- & $19.81 \pm 2.63$ & --- & $11.87 \pm 2.41$ \\
\hline Breast & --- & $39.03 \pm 0.54$ & --- & $15.15 \pm 3.56$ \\
\hline Heart wall & --- & $27.00 \pm 0.04$ & --- & $14.84 \pm 3.07$ \\
\hline Stomach wall & --- & $46.94 \pm 0.57$ & --- & $36.86 \pm 7.31$ \\
\hline Liver & --- & $47.71 \pm 1.17$ & --- & $36.23 \pm 7.16$ \\
\hline Gall Bladder & --- & $46.78 \pm 0.89$ & --- & $35.99 \pm 7.20$ \\
\hline Adrenals & --- & $41.75 \pm 0.79$ & --- & $31.23 \pm 6.20$ \\
\hline Spleen & --- & $47.99 \pm 1.45$ & --- & $37.64 \pm 7.48$ \\
\hline Pancreas & --- & $47.71 \pm 1.00$ & --- & $34.54 \pm 6.90$ \\
\hline Kidney & --- & $53.84 \pm 0.96$ & --- & $41.00 \pm 8.17$ \\
\hline Small intestine wall & --- & $48.68 \pm 0.26$ & --- & $37.24 \pm 7.43$ \\
\hline Colon wall & --- & $51.20 \pm 0.17$ & --- & $41.11 \pm 8.15$ \\
\hline Rectosigmoid wall & --- & $38.35 \pm 1.00$ & --- & $28.20 \pm 5.72$ \\
\hline Urinary bladder wall & --- & $42.59 \pm 1.29$ & --- & $27.85 \pm 5.88$ \\
\hline Prostate & --- & $17.23 \pm 4.57$ & --- & $7.51 \pm 1.67$ \\
\hline Uterus & --- & $38.15 \pm 0.92$ & --- & $27.66 \pm 5.62$ \\
\hline Gonads & --- & $25.92 \pm 1.08$ & --- & $17.78 \pm 3.55$ \\
\hline
\end{tabular}




\begin{tabular}{lllll}
\hline Skin & --- & $16.11 \pm 1.12$ & --- & $11.19 \pm 2.24$ \\
Muscle & --- & $20.68 \pm 1.64$ & --- & $11.52 \pm 2.27$ \\
Active marrow & --- & $14.78 \pm 1.36$ & --- & $12.96 \pm 2.55$ \\
Shallow marrow & --- & $20.33 \pm 1.44$ & --- & $13.03 \pm 2.63$ \\
$E_{60}$ & --- & $30.31 \pm 1.08$ & --- & $21.86 \pm 4.35$ \\
$E_{103}$ & --- & $31.20 \pm 1.03$ & --- & $21.67 \pm 4.32$ \\
\hline \hline
\end{tabular}

${ }^{\dagger}$ Abdomen-Pelvis.

Table 9: Organ dose (mean $\pm 1 \sigma$, mGy) and effective dose (mean $\pm 1 \sigma, \mathrm{mSv}$ ) derived from organ and tissue weighting factors from ICRP publications $60\left(E_{60}\right)$ and $103\left(E_{103}\right)$ for AP scan with contrast.

\begin{tabular}{|c|c|c|c|c|}
\hline $\begin{array}{l}\mathrm{AP}^{\dagger} \text { scan with } \\
\text { contrast }\end{array}$ & & & & \\
\hline organ or tissue & $<1 \mathrm{y}$ & $1-4 y$ & $5-9 y$ & $10-15 y$ \\
\hline Brain & $\begin{array}{l}-- \\
\end{array}$ & $0.60 \pm 0.04$ & $\begin{array}{l}-- \\
\end{array}$ & $0.15 \pm 0.03$ \\
\hline Pituitary gland & --- & $0.46 \pm 0.06$ & --- & $0.13 \pm 0.04$ \\
\hline Lens & --- & $0.61 \pm 0.08$ & --- & $0.16 \pm 0.04$ \\
\hline Eye balls & --- & $0.56 \pm 0.06$ & --- & $0.13 \pm 0.04$ \\
\hline Salivary glands & --- & $2.00 \pm 0.27$ & --- & $0.47 \pm 0.12$ \\
\hline Oral cavity & --- & $1.58 \pm 0.19$ & --- & $0.43 \pm 0.08$ \\
\hline Spinal cord & --- & $53.68 \pm 1.62$ & --- & $27.78 \pm 5.00$ \\
\hline Thyroid & --- & $5.33 \pm 0.71$ & --- & $1.32 \pm 0.23$ \\
\hline Oesophagus & --- & $16.04 \pm 3.07$ & --- & $16.04 \pm 3.07$ \\
\hline Trachea & --- & $6.20 \pm 0.21$ & --- & $2.85 \pm 0.51$ \\
\hline Thymus & --- & $10.84 \pm 0.77$ & --- & $3.66 \pm 0.83$ \\
\hline Lungs & --- & $40.80 \pm 3.91$ & --- & $20.00 \pm 3.53$ \\
\hline Breast & --- & $78.29 \pm 0.84$ & --- & $28.22 \pm 11.71$ \\
\hline Heart wall & --- & $53.98 \pm 0.05$ & --- & $24.80 \pm 4.58$ \\
\hline Stomach wall & --- & $93.86 \pm 1.07$ & --- & $63.03 \pm 11.90$ \\
\hline Liver & --- & $95.91 \pm 1.78$ & --- & $62.15 \pm 12.18$ \\
\hline Gall Bladder & --- & $93.93 \pm 1.36$ & --- & $61.11 \pm 10.94$ \\
\hline Adrenals & --- & $83.83 \pm 1.21$ & --- & $53.35 \pm 10.00$ \\
\hline Spleen & --- & $96.61 \pm 2.19$ & --- & $64.25 \pm 11.93$ \\
\hline Pancreas & --- & $95.86 \pm 1.53$ & --- & $58.75 \pm 10.62$ \\
\hline Kidney & --- & $108.09 \pm 1.47$ & --- & $69.86 \pm 12.78$ \\
\hline Small intestine wall & --- & $97.35 \pm 0.51$ & --- & $63.40 \pm 11.52$ \\
\hline Colon wall & --- & $102.37 \pm 0.35$ & --- & $70.37 \pm 13.39$ \\
\hline Rectosigmoid wall & --- & $76.70 \pm 1.85$ & --- & $47.55 \pm 8.38$ \\
\hline Urinary bladder wall & --- & $85.20 \pm 2.38$ & --- & $46.21 \pm 9.22$ \\
\hline
\end{tabular}




\begin{tabular}{lllll}
\hline Prostate & --- & $36.53 \pm 6.77$ & --- & $12.18 \pm 3.20$ \\
Uterus & --- & $76.69 \pm 1.40$ & --- & $46.60 \pm 8.22$ \\
Gonads & --- & $52.32 \pm 1.63$ & --- & $30.28 \pm 5.51$ \\
Skin & --- & $32.73 \pm 1.67$ & --- & $19.00 \pm 3.40$ \\
Muscle & --- & $42.08 \pm 2.44$ & --- & $19.98 \pm 4.54$ \\
Active marrow & --- & $29.60 \pm 2.48$ & --- & $22.50 \pm 5.17$ \\
Shallow marrow & --- & $40.69 \pm 2.63$ & --- & $22.03 \pm 3.88$ \\
$E_{60}$ & --- & $61.16 \pm 1.63$ & --- & $37.41 \pm 7.05$ \\
$E_{103}$ & --- & $62.90 \pm 1.56$ & --- & $37.26 \pm 7.29$ \\
\hline \hline
\end{tabular}

${ }^{\dagger}$ Abdomen-Pelvis.

Table 10: Organ dose (mean $\pm 1 \sigma$, mGy) and effective dose (mean $\pm 1 \sigma, \mathrm{mSv}$ ) derived from organ and tissue weighting factors from ICRP publications $60\left(E_{60}\right)$ and $103\left(E_{103}\right)$ for CAP scan without contrast.

\begin{tabular}{|c|c|c|c|c|}
\hline 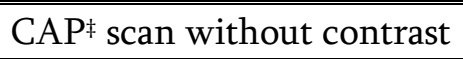 & & & & \\
\hline organ or tissue & $<1 \mathrm{y}$ & $1-4 y$ & $5-9 y$ & $10-15 y$ \\
\hline Brain & --- & $1.37 \pm 0.10$ & $1.09 \pm 0.07$ & $0.92 \pm 0.22$ \\
\hline Pituitary gland & --- & $1.30 \pm 0.22$ & $0.77 \pm 0.04$ & $0.72 \pm 0.17$ \\
\hline Lens & --- & $1.01 \pm 0.14$ & $0.67 \pm 0.04$ & $0.63 \pm 0.12$ \\
\hline Eye balls & --- & $1.06 \pm 0.14$ & $0.71 \pm 0.05$ & $0.61 \pm 0.13$ \\
\hline Salivary glands & --- & $6.77 \pm 0.91$ & $4.48 \pm 0.32$ & $3.69 \pm 0.90$ \\
\hline Oral cavity & --- & $4.50 \pm 0.52$ & $3.14 \pm 0.26$ & $2.63 \pm 0.48$ \\
\hline Spinal cord & --- & $42.54 \pm 1.66$ & $36.23 \pm 4.31$ & $22.29 \pm 4.13$ \\
\hline Thyroid & --- & $51.55 \pm 1.17$ & $46.41 \pm 4.59$ & $32.98 \pm 6.81$ \\
\hline Oesophagus & --- & $42.87 \pm 1.43$ & $37.85 \pm 3.28$ & $30.06 \pm 5.80$ \\
\hline Trachea & --- & $47.57 \pm 1.09$ & $42.82 \pm 4.19$ & $31.76 \pm 5.81$ \\
\hline Thymus & --- & $50.09 \pm 0.97$ & $45.63 \pm 4.28$ & $34.75 \pm 6.46$ \\
\hline Lungs & --- & $53.66 \pm 2.23$ & $46.46 \pm 3.88$ & $37.78 \pm 7.26$ \\
\hline Breast & --- & $43.58 \pm 1.19$ & $39.04 \pm 3.43$ & $31.42 \pm 5.63$ \\
\hline Heart wall & --- & $57.79 \pm 7.70$ & $49.10 \pm 4.21$ & $39.63 \pm 7.40$ \\
\hline Stomach wall & --- & $51.20 \pm 1.37$ & $46.11 \pm 3.82$ & $38.12 \pm 7.04$ \\
\hline Liver & --- & $52.73 \pm 1.70$ & $46.80 \pm 3.89$ & $38.72 \pm 7.07$ \\
\hline Gall Bladder & --- & $49.47 \pm 1.48$ & $44.21 \pm 3.63$ & $36.46 \pm 7.13$ \\
\hline Adrenals & --- & $47.10 \pm 1.65$ & $41.36 \pm 3.66$ & $32.75 \pm 6.10$ \\
\hline Spleen & --- & $53.22 \pm 2.09$ & $46.46 \pm 3.74$ & $38.90 \pm 7.29$ \\
\hline Pancreas & --- & $50.11 \pm 1.46$ & $44.63 \pm 4.01$ & $34.67 \pm 6.67$ \\
\hline Kidney & --- & $56.94 \pm 1.63$ & $50.90 \pm 4.40$ & $40.70 \pm 7.72$ \\
\hline Small intestine wall & --- & $49.75 \pm 0.77$ & $45.97 \pm 4.07$ & $36.13 \pm 6.88$ \\
\hline Colon wall & --- & $52.19 \pm 0.74$ & $48.55 \pm 4.08$ & $39.85 \pm 7.32$ \\
\hline Rectosigmoid wall & --- & $40.15 \pm 0.79$ & $36.56 \pm 3.43$ & $27.08 \pm 5.52$ \\
\hline Urinary bladder wall & --- & $45.97 \pm 0.37$ & $43.01 \pm 4.83$ & $26.59 \pm 6.03$ \\
\hline Prostate & --- & $20.94 \pm 3.55$ & $11.90 \pm 1.33$ & $7.16 \pm 1.79$ \\
\hline Uterus & --- & $39.57 \pm 0.83$ & $35.90 \pm 3.38$ & $26.51 \pm 5.42$ \\
\hline
\end{tabular}




\begin{tabular}{lllll}
\hline Gonads & --- & $27.38 \pm 0.83$ & $24.13 \pm 2.46$ & $17.12 \pm 3.25$ \\
Skin & --- & $23.41 \pm 1.40$ & $19.29 \pm 1.62$ & $15.65 \pm 3.00$ \\
Muscle & --- & $28.62 \pm 1.96$ & $22.60 \pm 2.55$ & $15.27 \pm 2.49$ \\
Active marrow & --- & $24.89 \pm 2.58$ & $18.48 \pm 0.94$ & $19.06 \pm 3.29$ \\
Shallow marrow & --- & $34.53 \pm 2.44$ & $27.43 \pm 2.59$ & $20.16 \pm 4.19$ \\
$E_{60}$ & --- & $41.81 \pm 1.37$ & $36.96 \pm 3.23$ & $29.49 \pm 5.51$ \\
$E_{103}$ & --- & $42.85 \pm 1.49$ & $37.81 \pm 3.25$ & $30.44 \pm 5.71$ \\
\hline \hline
\end{tabular}

‡ Chest-Abdomen-Pelvis.

Table 11: Comparison with established effective doses values from other studies.

\begin{tabular}{|c|c|c|c|c|c|}
\hline Head & $\begin{array}{c}\text { This study } \\
\text { (without/with } \\
\text { contrast) }\end{array}$ & $\begin{array}{c}\text { USA, } 2018 \\
{[14]}\end{array}$ & $\begin{array}{l}\text { South Korea, } \\
2015[17]^{* * *}\end{array}$ & $\begin{array}{l}\text { Germany, } \\
2007[18]\end{array}$ & $\begin{array}{l}\text { Malaysia, } \\
\text { 2020, [19] }\end{array}$ \\
\hline$<1 \mathrm{y}$ & 10.7/--- & 1.9 & 3.3 & 2.8 & 3 \\
\hline $1-4 y$ & $11.0 / 39.5$ & 2.5 & 1.8 & 2.6 & 2.2 \\
\hline $5-9 y$ & $9.2 / 23.2$ & 3.2 & 2.1 & 2.5 & 2.1 \\
\hline $10-15 y$ & $6.8 / 19.7$ & 3.5 & 1.8 & 2.7 & 3.6 \\
\hline \multicolumn{6}{|l|}{ Chest } \\
\hline$<1 \mathrm{y}$ & 16.4/--- & 1.4 & 2.8 & 2.6 & 1.3 \\
\hline $1-4 y$ & 6.6/--- & 3.5 & 2.6 & 3.2 & 1.6 \\
\hline $5-9 y$ & $---/ 16.6$ & 4.0 & 2.6 & 3.9 & 2.9 \\
\hline $10-15 y$ & $16.9 / 26.5$ & 3.9 & 3.1 & 4.4 & 4.0 \\
\hline \multicolumn{6}{|l|}{$\mathrm{AP}^{\dagger}$} \\
\hline$<1 \mathrm{y}$ & "---/--- & 2.8 & $\overline{5}$ & 4.9 & $\begin{array}{l}-- \\
\end{array}$ \\
\hline $1-4 y$ & $31.2 / 62.9$ & 6.5 & 5.9 & 5.6 & --- \\
\hline $5-9 y$ & ---/--- & 6.8 & 6.3 & 7.2 & --- \\
\hline $10-15 y$ & 21.7/37.3 & 8.2 & 6.0 & 8.0 & --- \\
\hline \multicolumn{6}{|l|}{ CAP } \\
\hline$<1 \mathrm{y}$ & $---/---$ & 4.3 & $\begin{array}{l}-- \\
\end{array}$ & --- & 1.6 \\
\hline $1-4 y$ & $42.9 / 85.2^{* *}$ & 7.2 & --- & --- & 3.0 \\
\hline $5-9 y$ & 37.8/--- & 7.7 & --- & --- & 6.8 \\
\hline $10-15 y$ & 30.4/--- & 11.1 & --- & --- & 11.7 \\
\hline
\end{tabular}

'Results for MC calculations and the use of ICRP publication 103 tissues weighting factors.

"Value received by a two-year old patient.

"*. This study used DLP-to-effective dose conversion factors.

†Abdomen-Pelvis.

‡ Chest-Abdomen-Pelvis. 


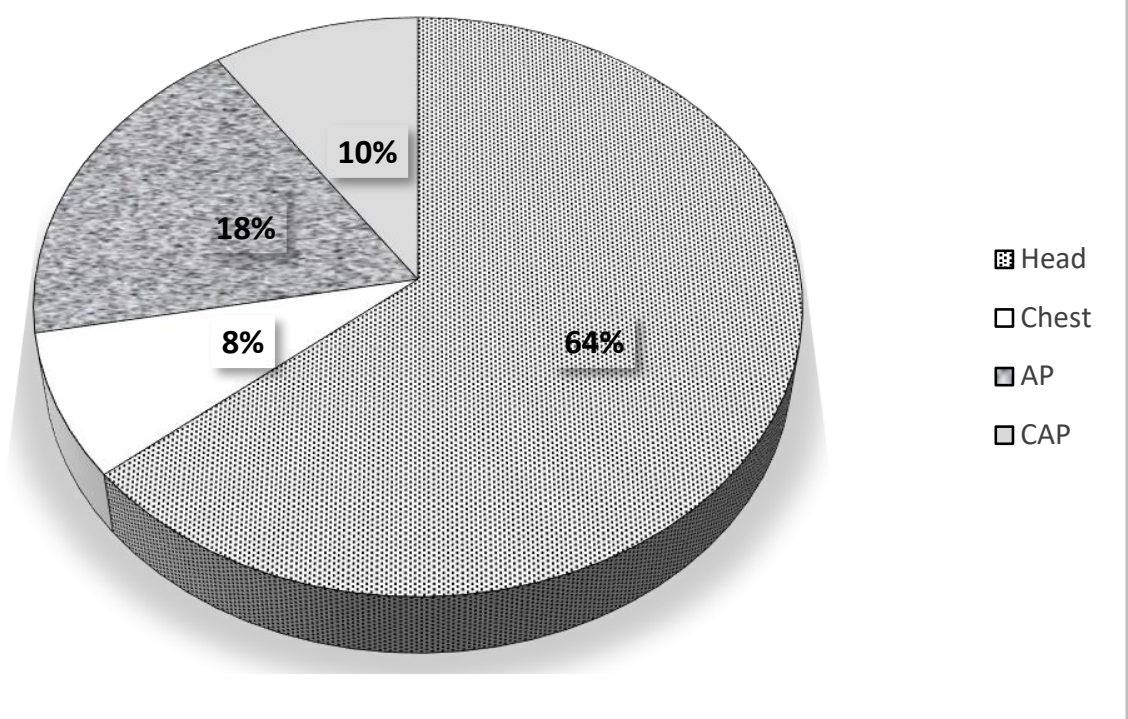

Figure 1: Repartition of patients per examination type in this study (AP = Abdomen-Pelvis, CAP $=$ Chest-Abdomen-Pelvis).

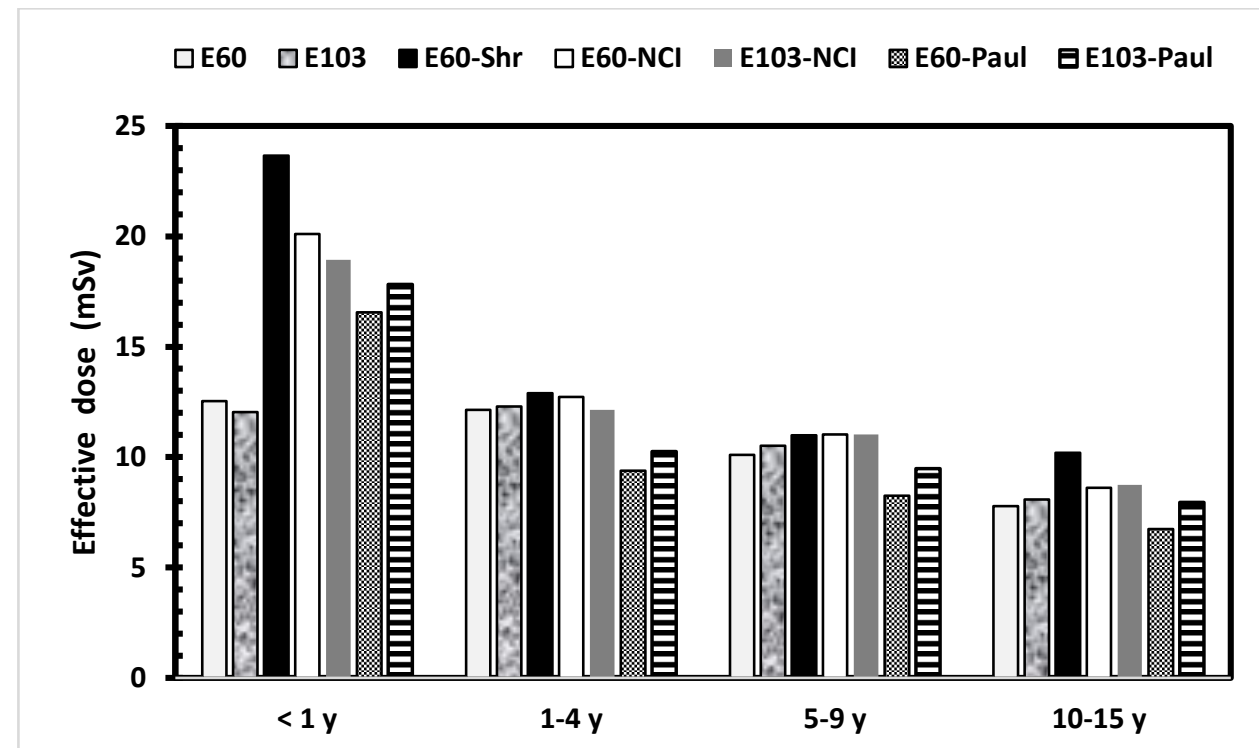

Figure 2: Comparison of MC based effective doses (E60 and $\left.\mathrm{E}_{103}\right)$ to $k$-factor based effective doses (E60-Shr, E60-NCI and E103-NCI, E60-Paul and E103-Paul) given in references [9, 11, 12], respectively - Head scan without contrast. 


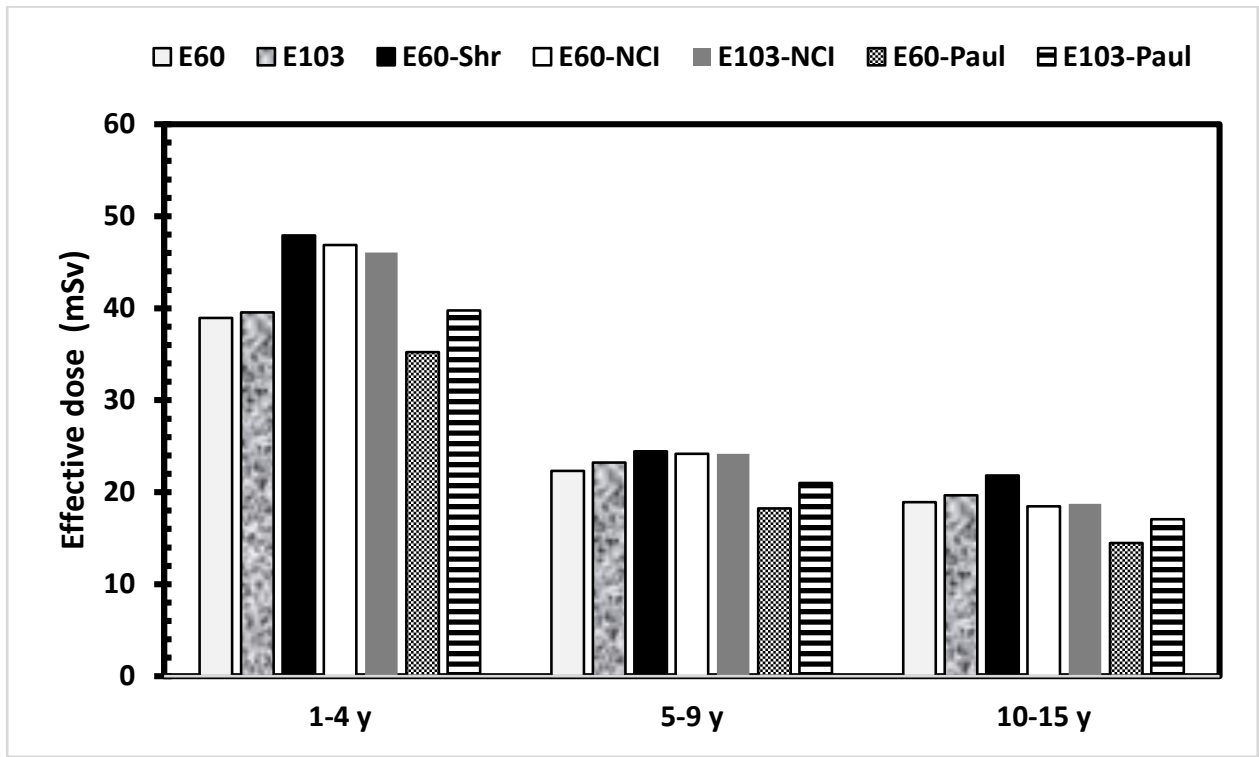

Figure 3: Comparison of MC based effective doses ( $\mathrm{E}_{60}$ and $\left.\mathrm{E}_{103}\right)$ to $k$-factor based effective doses (E60-Shr, $\mathrm{E}_{60} \mathrm{NCI}$ and E103-NCI, E60-Paul and E103-Paul) given in references $[9,11,12]$, respectively - Head scan with contrast.

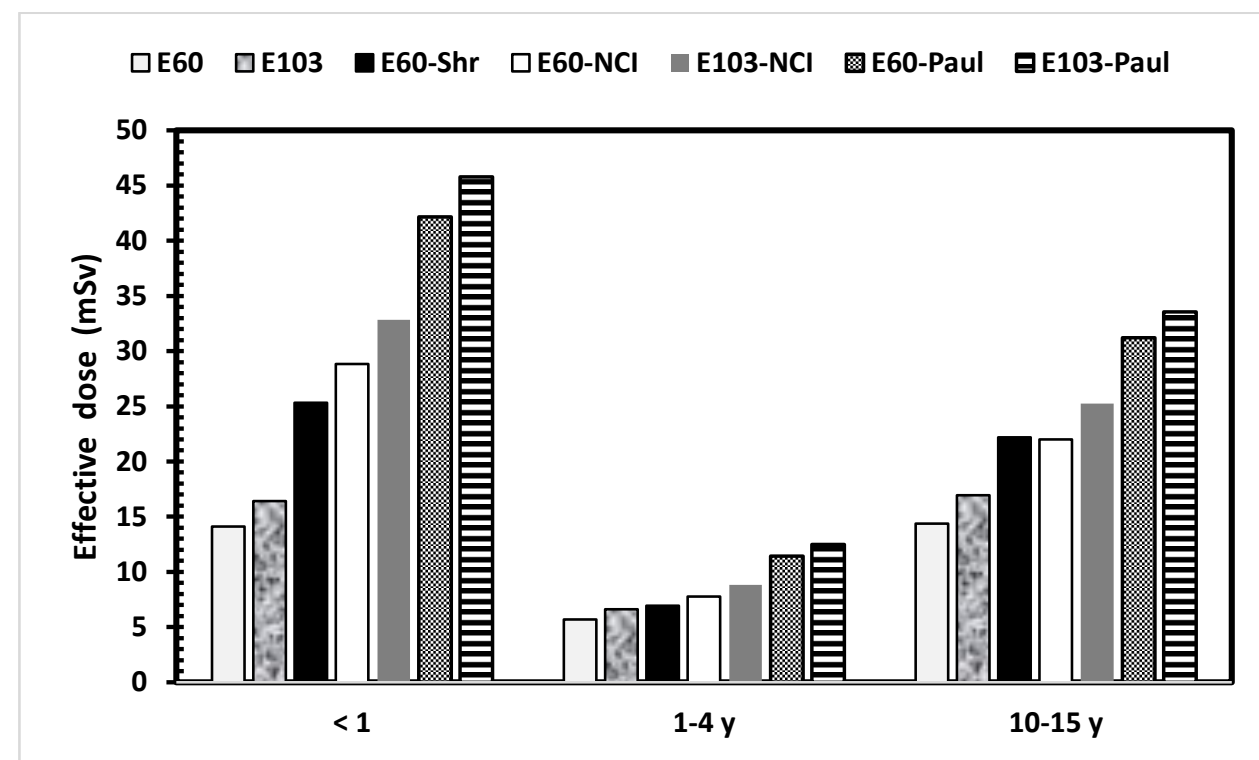

Figure 4: Comparison of MC based effective doses (E60 and $\mathrm{E}_{103}$ ) to $k$-factor based effective doses (E60-Shr, E60-NCI and $\mathrm{E}_{103-\mathrm{NCI}}$, E60-Paul and E103-Paul) given in references [9, 11, 12], respectively - Chest scan without contrast. 


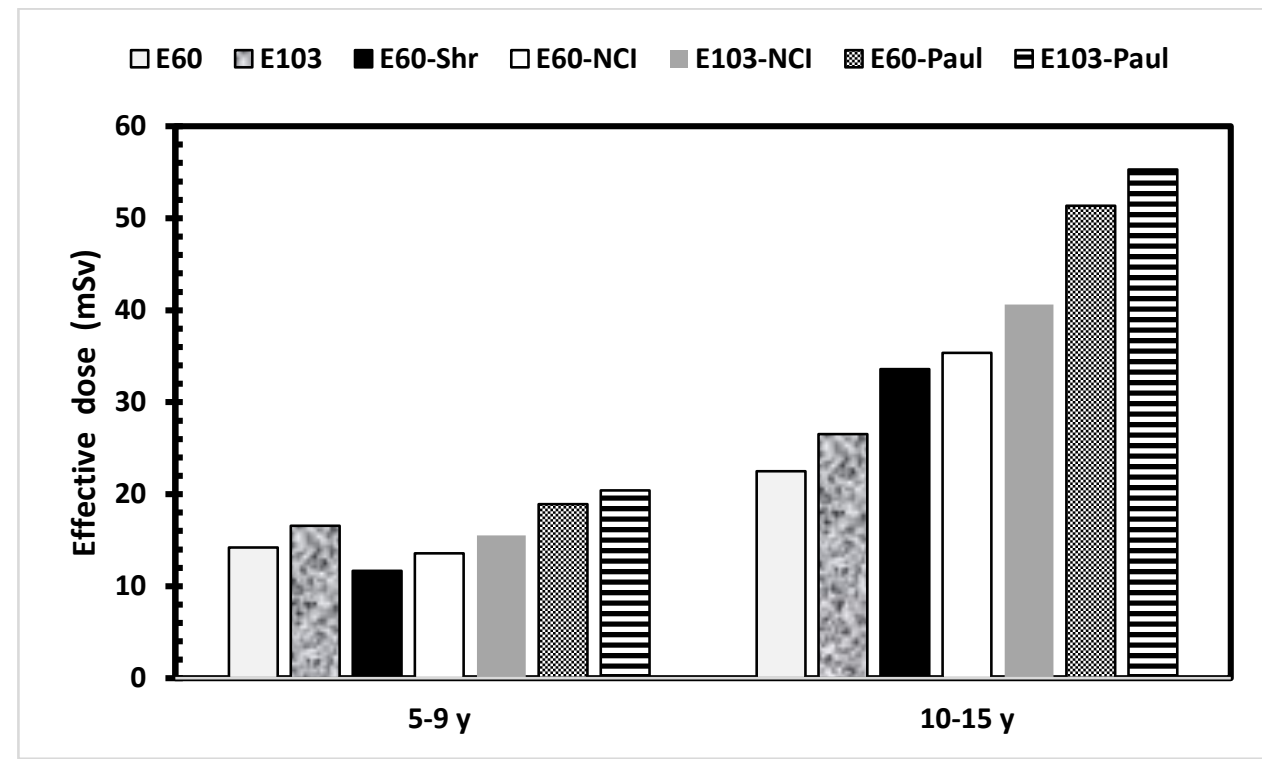

Figure 5: Comparison of MC based effective doses ( $\mathrm{E}_{60}$ and $\left.\mathrm{E}_{103}\right)$ to $k$-factor based effective doses (E60-Shr, $\mathrm{E}_{60} \mathrm{NCI}$ and E103-NCI, E60-Paul and E103-Paul) given in references $[9,11,12]$, respectively doses - Chest scan with contrast.

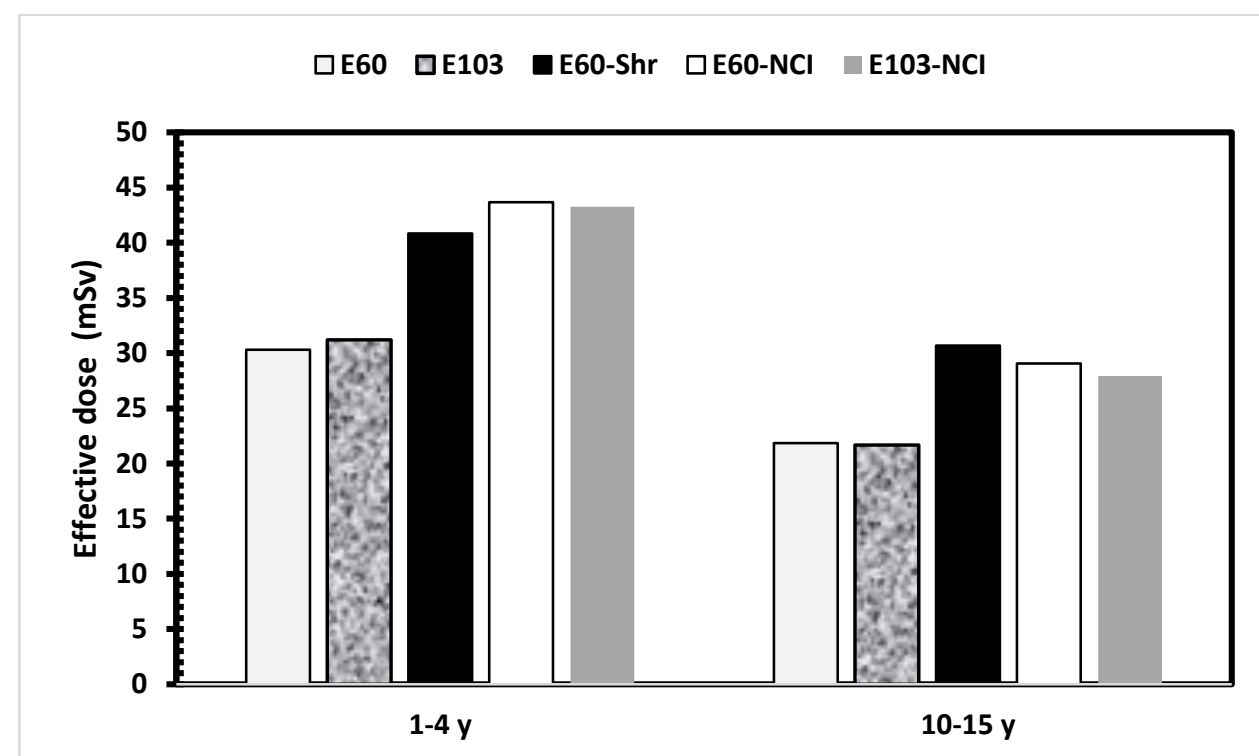

Figure 6: Comparison of MC based effective doses (E60 and $\left.\mathrm{E}_{103}\right)$ to $k$-factor based effective doses (E60-Shr, E60-NCI and E103-NCI, E60-Paul and E103-Paul) given in references $[9,11,12]$, respectively - AP scan without contrast. 


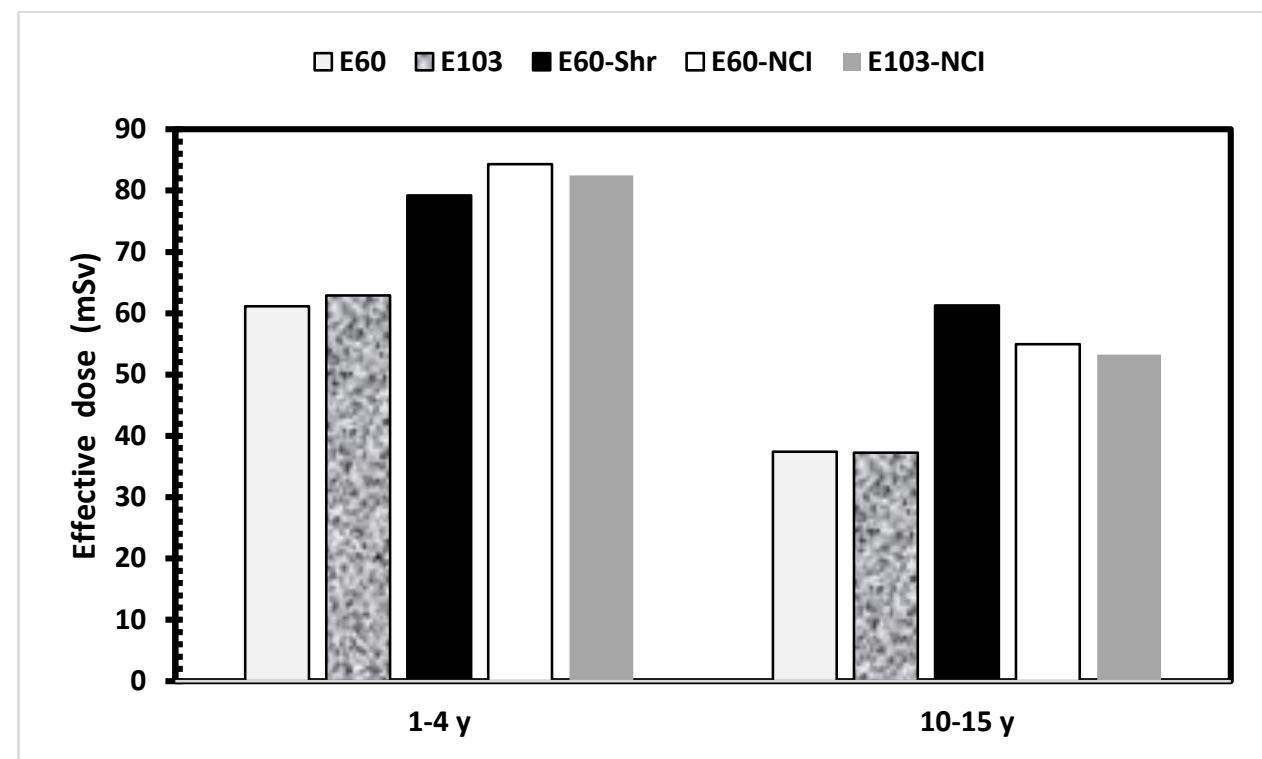

Figure 7: Comparison of MC based effective doses ( $\mathrm{E}_{60}$ and $\left.\mathrm{E}_{103}\right)$ to $k$-factor based effective doses (E60-Shr, E60-NCI and E103-NCI, E60-Paul and E103-Paul) given in references $[9,11,12]$, respectively - AP scan with contrast.

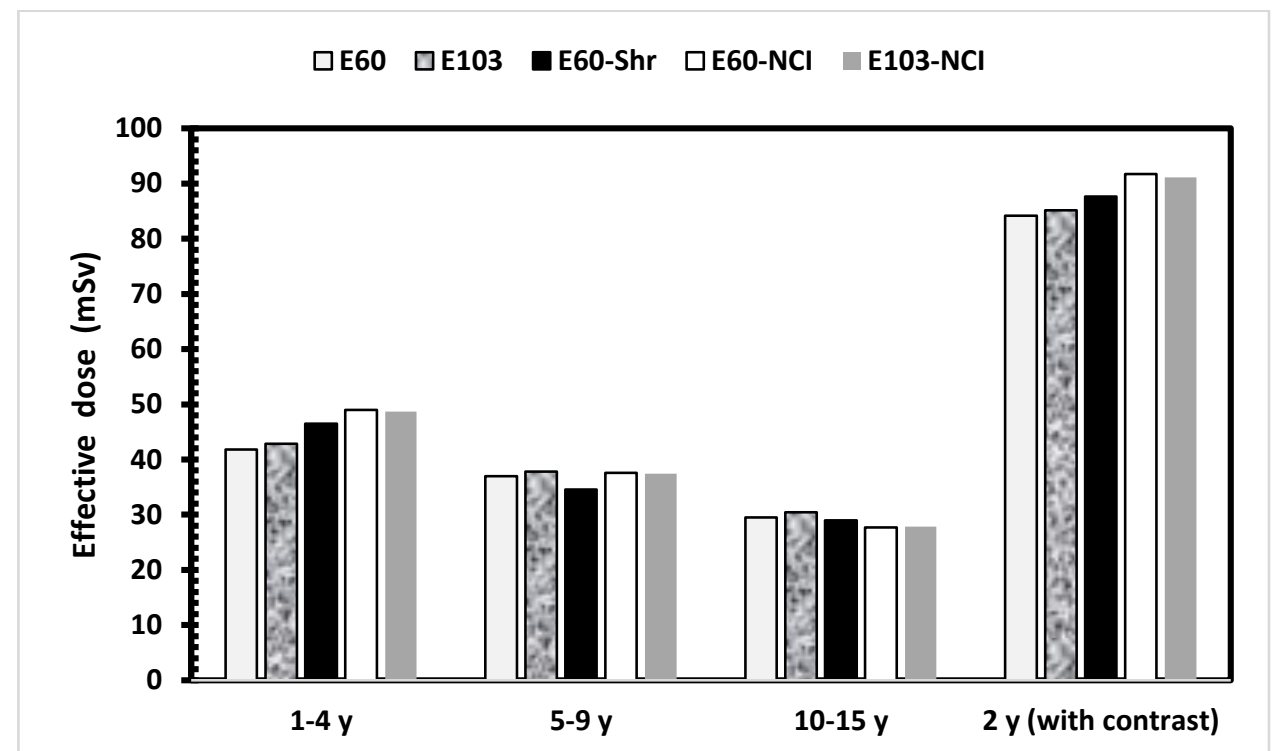

Figure 8: Comparison of MC based effective doses (E60 and $\mathrm{E}_{103}$ ) to $k$-factor based effective doses (E60-Shr, E60-NCI and E103-NCI, E60-Paul and E103-Paul) given in references [9, 11, 12], respectively - CAP scan. 